\title{
Interorganizational Knowledge Networks, R\&D Alliance Networks, and Innovation Capability: A Multilevel Network Perspective
}

\author{
Yan Zhao $\mathbb{D}^{1},{ }^{1}$ Xiao Han $\mathbb{D}^{2},{ }^{2}$ Xiaoran Yang $\mathbb{D},{ }^{1}$ and Zheng $\mathrm{Li}^{1}$ \\ ${ }^{1}$ School of Management, Shanghai University, Shanghai 200444, China \\ ${ }^{2}$ School of Management and Economics, North China University of Water Resources and Electric Power, \\ Zhengzhou 450046, China
}

Correspondence should be addressed to Xiao Han; hanxiao2018@shu.edu.cn

Received 20 September 2020; Revised 12 January 2021; Accepted 24 May 2021; Published 4 June 2021

Academic Editor: Yi Su

Copyright (c) 2021 Yan Zhao et al. This is an open access article distributed under the Creative Commons Attribution License, which permits unrestricted use, distribution, and reproduction in any medium, provided the original work is properly cited.

R\&D alliances and knowledge networks are vital to the innovation process. Based on the multilevel network approach, our study comprehensively investigates several knowledge attributes of interorganizational knowledge networks and explores how R\&D alliance networks are relevant for the relationship between knowledge attributes and organizational innovation capability. Samples in our research include 86 cliques from 2010 to 2015 in five Chinese high-tech industries' R\&D alliance networks. Results from the negative binomial regression model show that different knowledge attributes show a distinct effect on organizational innovation capability, including linear relationship, inverted U-shaped curve relationship, and inverted S-shaped curve relationship. Besides, our results identify that the central position within $\mathrm{R} \& \mathrm{D}$ alliance networks plays a limited role in the relationship between knowledge attributes and organizational innovation capability. Our findings could be used to help organizations sort out their knowledge attributes of knowledge bases, come to understand the impact of the interaction between the interorganizational knowledge network and R\&D alliance network on the organizational innovation capability, and then make a targeted strategy to carry out innovation activities.

\section{Introduction}

The emergence of the knowledge economy and information technology has increased the value of research and development $(\mathrm{R} \& \mathrm{D})$ alliances in a wide range of industries. In recent years, R\&D alliances have also developed rapidly in China. Previous researchers have conclusively shown that $\mathrm{R} \& \mathrm{D}$ alliance networks have potentially distributed a vast range of innovative benefits to organizations [1-3]. Organizations can mostly access diverse external knowledge from their alliance partners, which is particularly essential to improving their innovation capability [4]. However, when organizations aim to strengthen their innovation capability, some challenges are faced by innovation managers. How to get more innovative benefits from the R\&D alliance network to improve organizational innovation capability? What kind of knowledge combination strategy should be adopted in R\&D alliance networks to improve organizational innovation capability? Therefore, many scholars have extended from studying the $\mathrm{R} \& \mathrm{D}$ alliance network to its interorganizational knowledge networks. Our research sets out to investigate the innovation capability implications of interorganizational knowledge networks under the context of R\&D alliance networks.

As a vital component of networks, the clique is a group of mutually and directly linked actors in networks $[5,6]$. It is a microlevel network within networks possessing several unique structural characteristics. For example, the clique is a locally cohesive group, comprising groups of players linked but sparsely tied to others, which can span clique and connect actors located in distinct and otherwise disconnected cliques [7]. In addition, Phelps [8] asserted that the 
clique has an attribute of network closure (wherein an organization's cooperators are also cooperators), and some researchers suggest that the network closure can increase knowledge transfer and improve innovativeness $[9,10]$. Besides, a considerable amount of literature has been published on cliques $[6,11-13]$. These studies have reported that clique has emerged as a knowledge-sharing platform for alliance partners, and it, with a diverse knowledge base and fast direct connections, increases the probability of value creation. Thus, our study undertakes in-depth research on the vital component (cliques) of R\&D alliance networks and their interorganizational knowledge network.

In terms of interorganizational knowledge networks, Powell et al. [2] claimed that, as an industry's technology is widely distributed and rapidly developing, the locus of innovation would be found in interorganizational knowledge networks rather than within organizations. Currently, scholars have shown an increased interest in interorganizational knowledge networks and suggest that it is crucial for innovation outcomes [14-16]. However, researchers have tended to study the knowledge networks among inventors and neglected to explore the significance of the interorganizational knowledge networks that consist of all knowledge elements from alliance partners. Although one or two structural characteristics of interorganizational knowledge networks have been shown to affect organizational innovation capability [14], some additional knowledge attributes of interorganizational knowledge networks still need study further.

In addition, one major issue in recent research concerns the existence of an interaction effect between social networks (e.g., inventor networks and membership networks) and their intraorganizational knowledge networks [17-19]. Brennecke and Rank [17] found that knowledge networks' structural attributes can affect personal communication among inventors, thus influencing knowledge transfer and even the probability of knowledge recombination. This communication means that there is an interaction effect between inventor networks and their knowledge networks in the innovation process. Moreover, some researchers have shown that social networks among inventors and their interorganizational knowledge networks are decoupled $[14,20]$. Overall, several studies have examined the interaction effects between social networks and interorganizational knowledge networks or intraorganizational knowledge networks. However, few researchers investigated the intereffect between alliance networks and their interorganizational knowledge networks. Therefore, in this study, we fill this gap and explore how $R \& D$ alliance networks among organizations are relevant for the relationship between interorganizational knowledge networks and organizational innovation capability.

Our research provides new insights into the study of interorganizational knowledge networks. First, most prior studies paid more attention to the field of intraorganizational knowledge networks, while only a few studies investigated interorganizational knowledge networks [14-16]. Guan and Liu [14] examined several structural characteristics of interorganizational knowledge networks that may affect innovation outcomes. To extend this research, our study applied a multilevel network method [17-19] to examine additional knowledge attributes of interorganizational knowledge networks. Second, since few studies have examined the relationship between alliance networks and knowledge networks in the interorganizational research field, our study explores the interaction effect between R\&D alliance networks and their interorganizational knowledge networks further. Specifically, the R\&D alliance networks' structural attribute is chosen to test how it influences the relationship between interorganizational knowledge networks and organizational innovation capability.

The purpose of our study is to address these gaps based on the multilevel network approach. Our research emphasizes the central position within alliance networks to provide a new dimension to study the relationships between interorganizational knowledge networks and organizational innovation capability. Within the developed research framework, our study addresses the two following research questions:

Question 1. How do knowledge attributes of interorganizational knowledge networks (knowledge combinatorial potential, knowledge uniqueness, knowledge diversity, and knowledge proximity) bring about organizational innovation capability?

Question 2. How does the structural attribute of $R \& D$ alliance networks (e.g., degree centrality) moderate the relationship between knowledge attributes of interorganizational knowledge networks and organizational innovation capability?

\section{Theoretical Framework}

2.1. Research and Development Alliance Networks. Previous studies mostly defined R\&D alliances as innovation-based relationships established by several actors who collaborate to develop a new product or technology [21, 22]. Following previous researchers $[8,23]$, our study has used similar alliance network construction criteria to develop the R\&D alliance network. An R\&D alliance network consists of organizations and their R\&D cooperation relationships. For example, CHANGAN, GEELY, Alibaba, and AutoNavi established an R\&D cooperation relationship since they aim to co-research a new navigation system generation; Similarly, Alibaba cooperates with SAIC Motor to jointly develop Internet cars; Baidu and GEELY cooperate to research AI smart cars and explore intelligent travel. As the nodes in R\&D alliance networks, organizations linked by $R \& D$ partnerships can control knowledge diffusion and subsequent innovative outcomes [14]. Additionally, the ties among these organizations can serve as a means to attain knowledge and information through alliance partners. Current studies have shown that R\&D alliance networks are regarded as one of the most useful tools for acquiring external knowledge [24], thereby providing a channel for knowledge transfer and recombination [25].

Moreover, organizations located in different positions within alliance networks might influence innovation 
outcomes $[8,26,27]$. Centrality is a significant indicator to present organizations' location in networks, which refers to the number of links incident upon an organization in alliance networks [28]. In our research, three types of centrality (degree centrality, betweenness centrality, and closeness centrality) will be explored. We choose degree centrality as the moderating variable to test the relationships between interorganizational knowledge networks and organizational innovation capability for the following reasons. First, the structural characteristics of degree centrality, or the number of alliance partners' link to a focal organization, show the distance from the center position of networks. Second, as Freeman [28] suggested, degree centrality is an ideal centrality indicator for seizing an actor's access to knowledge in networks. Third, degree centrality is more likely to associate with the relationship between interorganizational knowledge networks and organizational innovation capability. Organizations with a higher level of degree centrality in their alliance networks, linked to many other alliance partners (e.g., Figure 1(a) shows that GEELY connects two cliques, indicating it has a higher degree centrality than other alliance partners), imply richer external cooperation relations and higher capability to control knowledge resources in interorganizational knowledge networks than organizations with a lower level of degree centrality [29]. Besides, organizations with a higher degree centrality in $R \& D$ alliance networks are more likely to acquire more information from their interorganizational knowledge networks than those located on edge [30,31], and they will gain experience and master the necessary skills to enrich their knowledge bases and enhance their innovation capabilities. Therefore, an interaction effect between interorganizational knowledge networks and R\&D alliance networks can be predicted, that is, the different levels of degree centrality might moderate the impact of interorganizational knowledge networks on the organizational innovation capability.

\subsection{Interorganizational Knowledge Networks. Knowledge} elements are the essential components of knowledge networks. It can be defined as a category that includes a series of facts, concepts, methods, insights, or procedures related to a subject $[20,32]$. In our research, technological knowledge elements are the key components in knowledge networks. Following previous research $[8,17,20,33]$, our study uses the four-digital International Patent Classification (IPC) code of patents as knowledge elements to develop the interorganizational knowledge network. The four-digital IPC code combines a section, class, and subclass, which can adequately capture the characteristics of patents [14].

Knowledge network is derived from an agglomeration of links among knowledge elements [34-36]. In our research, the interorganizational knowledge network consists of all knowledge elements of alliance partners and the relationships between knowledge elements. Consistent with previous research [34-36], the ties that link knowledge elements in interorganizational knowledge networks are represented by knowledge combinations in history and co-application of knowledge elements in patents, and if two organizations have one common knowledge element, the two groups of knowledge elements linked to this knowledge element would establish indirect connections. Figure 1 presents an example of an interorganizational knowledge network. As shown in Figure 1(a), there is a cohesive subgroup containing two cliques. One clique consists of CHANGAN, GEELY, Alibaba, and AutoNavi, aiming to co-research a new navigation system generation. Another clique consists of GEELY, VOLVO, and Geely Zhaoyuan, aiming to establish an R\&D center for automobile parts. CHANGAN, GEELY, and VOLVO are automobile companies, and they have very similar knowledge bases. Figure 1(b) presents their interorganizational knowledge network showing the connections of knowledge elements among these organizations. It can be seen that these knowledge elements are automatically divided into several groups. Some knowledge elements are located at the edge, while some are located at the center of the interorganizational knowledge network.

2.3. Two-Mode Networks. The two-mode network is frequently used to show the relations between individuals and their parties or events with which these individuals are affiliated [37]. Thus, the two-mode network is also named affiliation networks [38]. Following Wasserman and Faust [38], we extend the conception of affiliation from a broad perspective to contain knowledge elements in organizations and alliances. Figure 1(c) shows their two-mode network, which links the R\&D alliance networks to their interorganizational knowledge network. It can be seen that these five organizations (red nodes) connect to their knowledge elements (white nodes) in the two-mode network (Geely Zhaoyuan do not have knowledge elements). Moreover, after weighting the two-mode network, as shown in Figure 1(d), it can be seen that GEELY has 116 common knowledge elements with CHANGAN and 32 same knowledge elements with VOLVO. It also has many other fields of knowledge elements that the other five organizations do not possess, which indicates that GEELY's knowledge elements occupy a higher centrality in the interorganizational knowledge network. AutoNavi is a web mapping, navigation, and location-based services provider that masters a unique technology in the research program. Conversely, these knowledge elements of Alibaba and Geely Zhaoyuan are in a lower centrality position within their interorganizational knowledge network. Thus, these two companies might not benefit more from their alliance partners. Therefore, the location of knowledge elements in interorganizational knowledge networks might influence the organizational innovation capability [14].

2.4. Multilevel Networks. There is no clear and unified definition of the multilevel network. Previous scholars divided it into the multiplex network, timing network, network of network, interdependent network, and other different types according to the characteristics of the topological structure. In our study, we adopted the concept of the interdependent network. Buldyrev et al. [39] proposed that due to technological progress, modern systems are 


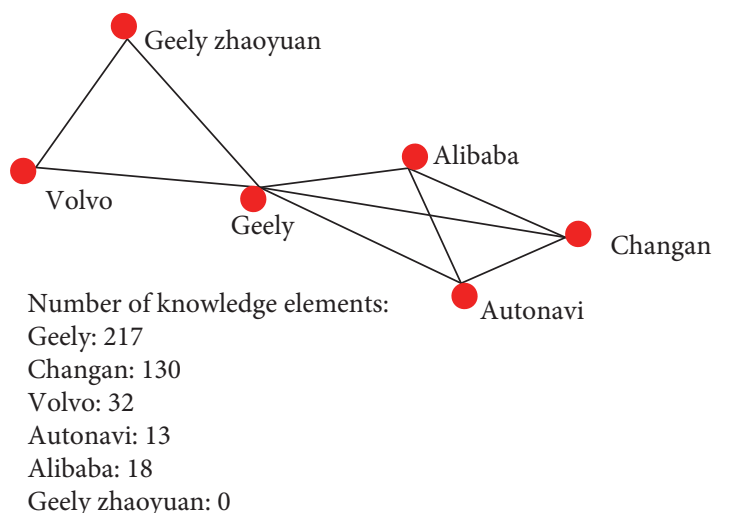

Knowledge elements

Organizations

(a)

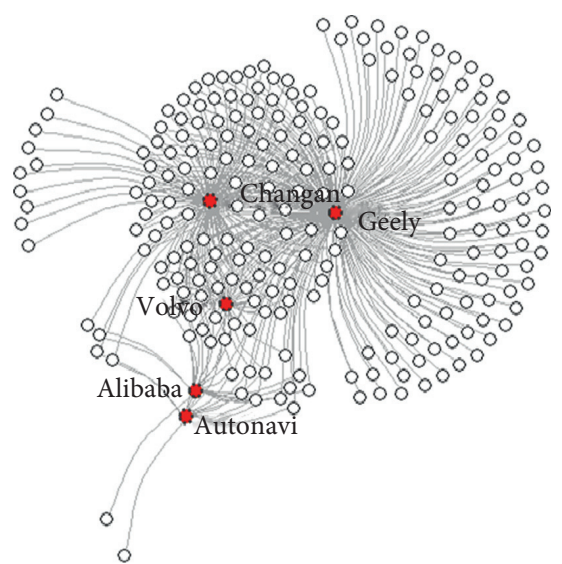

Knowledge elements

Organizations

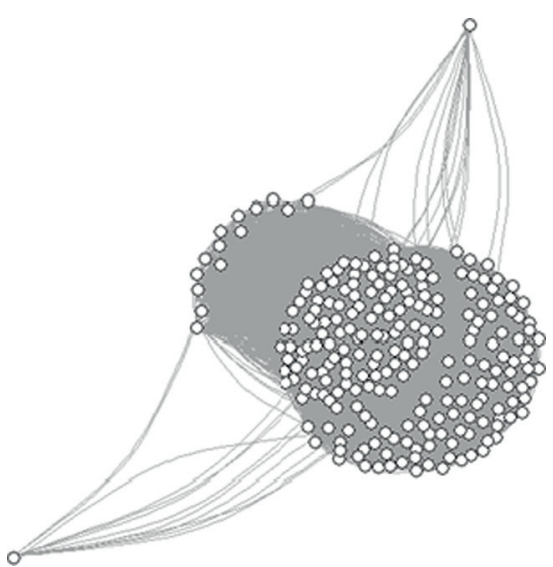

Knowledge elements

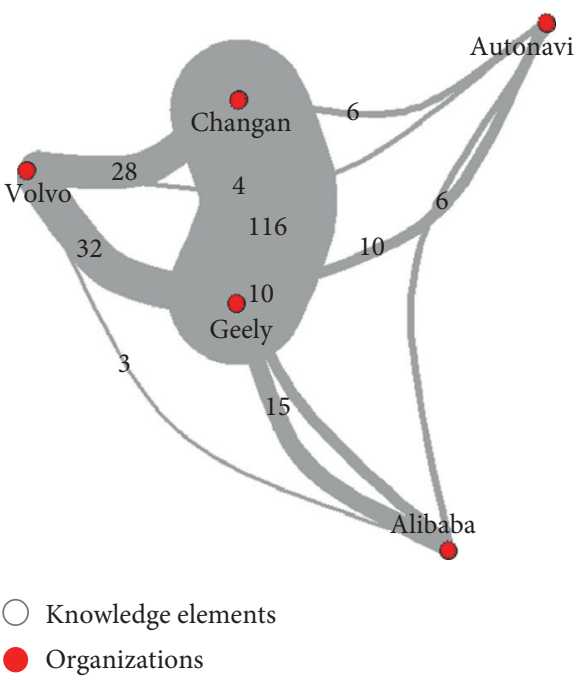

(d)

FiguRE 1: A case of interorganizational knowledge networks: (a) subgroup; (b) interorganizational knowledge network; (c) two-mode network; (d) weighted two-mode network, the weight is the number of same knowledge elements between two organizations.

becoming more and more coupled together. While in the past many networks would provide their functionality independently, modern systems depend on one another to provide proper functionality. For example, in our research, R\&D alliance networks and their interorganizational knowledge networks are all one-mode networks and there exists a dependence relation between them. Knowledge elements in interorganizational knowledge networks are dependent or belong to organizations in $R \& D$ alliance networks. Organizations located in distinct network positions may affect the effectiveness of their knowledge combination in interorganizational knowledge networks, and the organizations' knowledge elements located in different positions of interorganizational knowledge networks may affect the organization's choice of its future alliance partners.

Previous researchers $[17,39-41]$ proposed that the interdependent multilevel network is composed of two or $n$ single networks. The nodes in a single network are homogeneous, while the nodes between every single network are of different types. Besides, a multilevel level network has nodes of several different types, and each type represents a different level. A one-mode network can be defined within each level, and a bipartite (two-mode) network can be defined between nodes from two adjacent levels. Therefore, following previous research methods of multilevel network construction $[17,39-41]$, in our study, we developed a new multilevel network (see Figure 2), which includes three levels. That is, the nodes (organizations) at the below level, which is labeled as an R\&D alliance network, the nodes (knowledge elements) at the top level, which is labeled as an interorganizational knowledge network, and the middlelevel bipartite network as a two-mode network, which links each organization within $R \& D$ alliance networks to single knowledge elements, reflecting organization embeddedness in the interorganizational knowledge network. From Figure 2, we can see that some alliance partners share common 


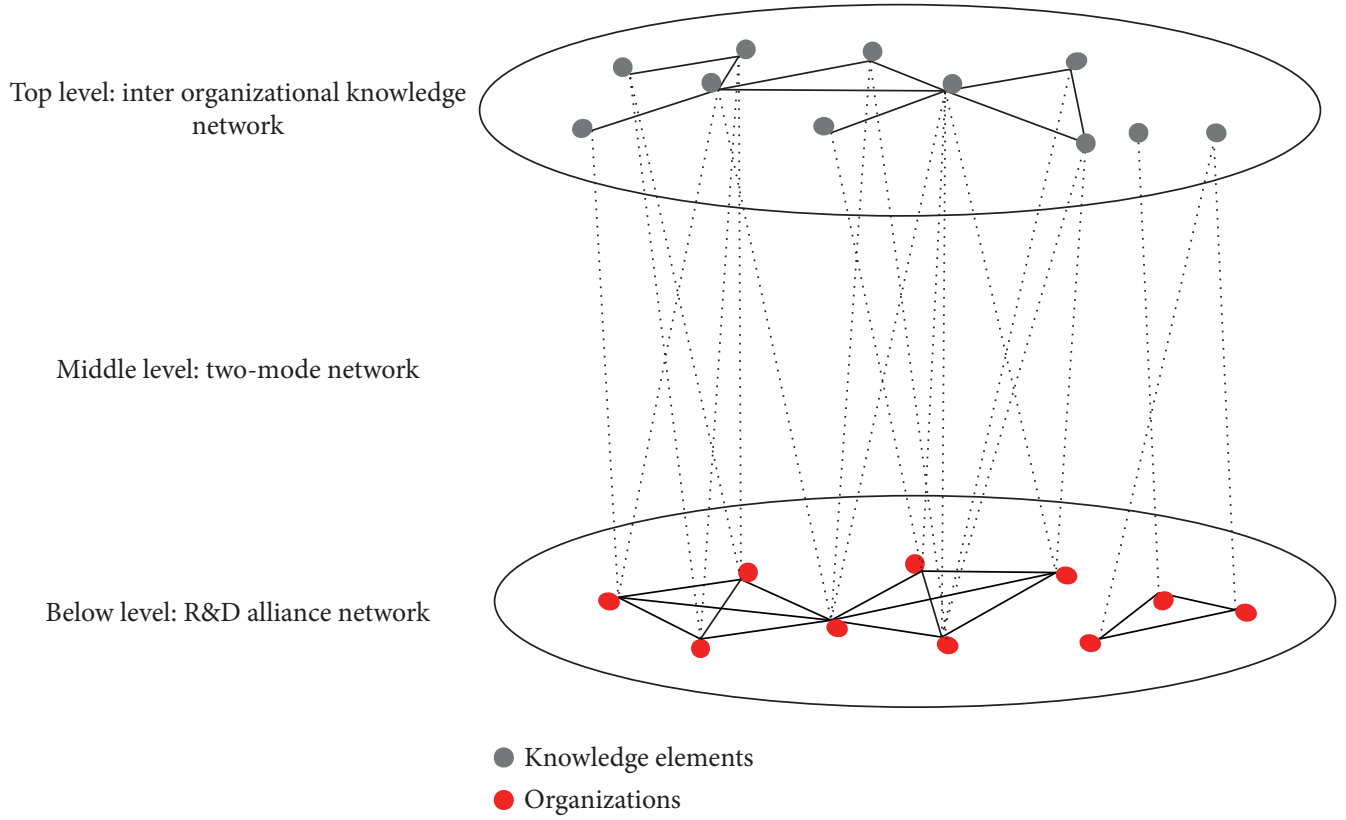

FIgURE 2: Overview of the theoretical framework of the multilevel network.

knowledge elements, and compared to others, some organizations possess a diversified knowledge base. Furthermore, some knowledge elements within their interorganizational knowledge network link many organizations, and some knowledge elements only connect to one or two organizations. Therefore, some knowledge attributes can be captured by the position of knowledge elements in interorganizational knowledge networks or the connection between knowledge elements and organizations. Consistent with Wang et al. [20] and Brennecke and Rank [17], our study classifies knowledge attributes into four categories: knowledge combinatorial potential, knowledge uniqueness, knowledge diversity, and knowledge proximity.

\subsection{Hypotheses' Development}

2.5.1. Knowledge Combinatorial Potential and Degree Centrality. Knowledge combinatorial potential draws on the connections between various knowledge elements, which were dependent on the knowledge combinatorial record in the past [42], and it is typically measured by the degree centrality of knowledge elements in knowledge networks $[14,17,20]$.

A knowledge element with a higher degree centrality tends to present a high combinatorial potential in knowledge networks. The main reason is that knowledge elements with a higher degree centrality could increase the probability of knowledge combination, which would benefit organizations carrying out innovation activities and stimulate new ideas generation $[14,20]$. For example, as in the case we discussed above, knowledge elements of automobile companies (e.g., GEELY and CHANGAN) have a higher degree centrality in their interorganizational knowledge network. Therefore, the knowledge combinatorial potential of these two companies might be higher than other alliance partners. Besides, organizations with a high combinatorial potential knowledge stock can integrate or connect more knowledge elements from different technology fields. For instance, hightech firms tend to cooperate with traditional industries and upgrade their products (e.g., autonomous vehicles and smart home). Similarly, knowledge elements with higher combinatorial potential might be related to the subject matter [20], which might attract organizations with this local knowledge element to search for combinatorial spaces.

In summary, it can be predicted that knowledge combinatorial potential has a positive influence on organizational innovation capability, especially in an organization with a high knowledge combinatorial potential. Therefore, we suggest the following:

Hypothesis 1. Knowledge combinatorial potential positively influences organizational innovation capability.

Moreover, organizations with a central position (a higher degree centrality) within R\&D alliance networks might affect the relationship between knowledge combinatorial potential and organizational innovation capability. Degree centrality is one of the critical indicators to present the central position of an actor in alliance networks, which is regarded as the number of cooperators that an actor is directly linked in alliance networks [22]. Degree centrality reflects a real-world situation in which organizations with a high degree centrality can control more resources and information in $R \& D$ alliance networks, enhance their commercial standing, and influence how their capabilities are perceived [43]. Nerkar and Paruchuri argued that degree centrality creates an attractiveness for prospective alliance partners to select new knowledge elements [44], and it is regarded as a source of innovativeness because an organization with a central position has more opportunities to access external information that is difficult to obtain in the 
market [43]. Besides, an organization located in a central position in alliance networks would have more chances to discover unexplored combinations, making it easy to appeal to other organizations that cooperate with influential organizations [45] and have timely access to promising projects, resulting in several subsequent $\mathrm{R} \& \mathrm{D}$ collaborations [2].

Therefore, our study posits that the different levels of degree centrality change the effect that the knowledge combinatorial potential has on the organizational innovation capability. Organizations with a low level of degree centrality are generally located at the edge of alliance networks and connected to fewer alliance partners. In this case, even though organizations have a high knowledge combinatorial potential, it is challenging to generate new combinations because they cannot access rich knowledge resources. However, if an organization has a high level of degree centrality in its alliance networks, it will support it to access external knowledge resources. Thus, even though the organization has less knowledge combinatorial potential, it still could benefit more from the frequent communication and diverse external knowledge resources.

With this logic, we further predict that degree centrality in $\mathrm{R} \& \mathrm{D}$ alliance networks can positively affect the relationship between knowledge combinatorial potential and organizational innovation capability. That is, when an organization has a low knowledge combinatorial potential, the frequent communication and intensity of knowledge transferring created by the high degree centrality in its alliance networks can steer its alliance partners to share their knowledge and technologies and, thus, more effectively facilitate the organization to acquire and combine the external knowledge shared by its alliance partners [46]. As the knowledge combinatorial potential increases, it can further benefit from the rich external resources brought about by the high degree centrality of R\&D alliance networks.

In summary, degree centrality depending on intense connections facilitates a central organization to access diverse knowledge elements [47]. The benefits brought by degree centrality can positively moderate the effect of knowledge combinatorial potential on organizational innovation capability. Therefore, based on previous research, our study tends to examine this hypothesis:

Hypothesis 2. Degree centrality plays a positive moderating role in the relationship between knowledge combinatorial potential and organizational innovation capability.

\subsubsection{Knowledge Uniqueness and Degree Centrality.} Knowledge uniqueness can be defined as organizations being knowledgeable in a field that other partners are unfamiliar with [17]. Organizations are linked to several knowledge elements in their interorganizational knowledge networks that few other partners are linked to, which may affect knowledge combination. Scholars have long debated the impact of knowledge uniqueness on innovation outcomes.

Previous researchers have claimed that access to unique knowledge resources can be valuable for the organization
[47]. Organizations with a certain number of unique knowledge elements might have advanced technology in some fields, attracting other organizations' attention and cooperation. This unique knowledge is better for carrying out a competitive strategy of differentiation as unique information and technology are sources of competitive parity [48]. Besides, organizations posses rare knowledge elements that are uncommonly distributed in a market. Thus, their unique knowledge is quaint to any competitors and is also a valuable property for organizational innovation.

However, some researchers have recently shown that organizations possessing an abundance of unique knowledge bases might reduce external exploration and thus less actively search for new information from their alliance partners [49]. Uniqueness is considered the degree of the knowledge's content specificity, which is not easy to transfer to other organizations or even difficult for other organizations to duplicate. That could be why it is not easy to be innovative based on unique knowledge [50]. Besides, with unique knowledge elements in their knowledge bases increasing, the knowledge protection mechanism might switch on and reduce external exploration, affecting knowledge sharing and transfer among alliance partners and eventually influencing organizational innovation capability in the long run.

As mentioned above, our study posits an inverted $\mathrm{U}$-shaped relationship between knowledge uniqueness and organizational innovation capability. When the number of an organization's unique knowledge is lower, the organizational innovation capability may suffer from lacking core competitiveness in the market. As its knowledge uniqueness increases, the enhanced unique knowledge elements will enable an organization to benefit from its differentiated knowledge resources and appeal to more $R \& D$ ventures, thus improving its innovation capability. However, such enhanced unique knowledge elements will also commensurately hinder the knowledge transfer between organizations and their alliance partners because as the unique knowledge is possessed too much, the communication barriers and cost may exceed the knowledge-sharing benefits. Therefore, we propose this hypothesis:

Hypothesis 3. Knowledge uniqueness has an inverted $\mathrm{U}$-shaped effect on organizational innovation capability.

Moreover, organizations with a central position in $R \& D$ alliance networks might influence the relationship between knowledge uniqueness and organizational innovation capability. Regarding the high degree centrality, organizations located in a central position in their R\&D alliance network have many direct connections, enabling organizations to carry out more innovative activities and R\&D programs with their alliance partners. That means organizations with a high degree centrality could access and control more diverse information from their alliance partners or deciding on new investment in R\&D projects [47], which might facilitate them to carry out external innovation exploration and search for new knowledge combinations.

Our study posits that the different levels of degree centrality change the effect that the knowledge uniqueness 
has on the organizational innovation capability. That is, organizations with a high level of degree centrality might make up for the shortcomings of excessive unique knowledge elements that weaken innovation outcomes because the high degree centrality supports rich external cooperation relations and knowledge resources [29]. High degree centrality has implications for high levels of knowledge sharing in knowledge networks [51]. In other words, as an organization's degree centrality in its R\&D alliance network is high, the enhanced mutual communications among alliance partners can promote the organization to share, combine, and transfer its unique knowledge effectively. Besides, intensifying mutuality enables alliance partners to share unique knowledge and generate innovations that cannot be achieved separately in $\mathrm{R} \& \mathrm{D}$ alliances [46]. As a result, the high degree centrality can effectively advance R\&D cooperation and knowledge transferring among alliance partners and make up for the shortcomings of excessive unique knowledge elements that bring high cost of new knowledge combinations.

On this logic, we further assume that degree centrality can moderate the inverted U-shaped effect of the knowledge uniqueness on the organizational innovation capability. That is, when the knowledge uniqueness is weak, the frequent communication and intensity of knowledge sharing created by the high degree centrality enables the alliance participants to share their knowledge and information, thereby facilitating local organizations to timely access the external resources provided by their alliance partners [52]. As the knowledge uniqueness increases, it can further benefit from the high degree centrality of organizations with cohesive connections, which compensate for the organizations with an overabundance of unique knowledge that is difficult for transferring and combining new knowledge elements in interorganizational knowledge networks.

In summary, as the degree centrality of organizations gets higher, the benefits from the degree centrality tend to be enhanced, making the curve of inverted U-shaped effect of knowledge uniqueness on the organizational innovation capability weaker. Overall, our study poses this hypothesis:

Hypothesis 4. Degree centrality plays a moderating role in the relationship between knowledge uniqueness and organizational innovation capability.

\subsubsection{Knowledge Diversity and Degree Centrality.} Knowledge diversity can be defined as an abundance degree of knowledge elements, which is similar to technology diversity $[8,53]$. In our research, knowledge diversity tends to be used to refer to the extent of an organization's knowledge diversity within its interorganizational knowledge network. Scholars have long debated the significance of knowledge diversity.

Many studies [54-56] have shown that knowledge diversity increases the probability of knowledge combinations and enhances organizations' capability for problem solving. By maintaining an extensive knowledge combination, organizations can explore and exploit new opportunities derived from diversified knowledge stock [57, 58]. Furthermore, knowledge diversity can act as a catalyst for innovation and knowledge transfer [59]. In particular, for high-tech industries, continuously acquiring diversified knowledge in technology fields is essential for survival [60].

However, some researchers have suggested that overdiversified knowledge might affect organizational absorptive capability. As knowledge diversity increases, the technological distance among alliance partners becomes more extensive, which might weaken their ability to recognize and absorb new knowledge and expand the cost of innovation activities [35, 61]. This enormous R\&D funding investment might disrupt the regular operation of organizations. Notably, some small-scale organizations do not have strong cognitive capabilities and rich experiences to comprehend overdiversified knowledge [36]. Besides, seeking to grasp and integrate highly diverse knowledge elements can cause information overburden $[8,62]$.

Therefore, our research posits an inverted U-shaped relationship between knowledge diversity and organizational innovation capability. When the number of an organization's diverse knowledge is lower, the organizational innovation capability may suffer from lacking novel knowledge elements to combinate. As its diverse knowledge increases, the enhanced new knowledge elements will enable organizations to benefit from new combinations and products, thus improving their innovation capability. However, such enhanced diverse knowledge bases will also increase high $\mathrm{R} \& \mathrm{D}$ costs. When the diverse knowledge is possessed too much, the cost may exceed the knowledge combination benefits, and the marginal revenue would be reduced generally by the overnumber of diverse knowledge elements. Thus, we propose this hypothesis:

Hypothesis 5. Knowledge diversity has an inverted U-shaped effect on organizational innovation capability.

Moreover, organizations with a central position within R\&D alliance networks might affect the relationship between knowledge diversity and organizational innovation capability. Organizations with a leading position are considered reference objects for other alliance partners, influencing the likelihood of new knowledge combinations and potential causes of operating losses [63]. The bright side is that organizations from the central location in networks could establish a higher standing, reduce their risk perception in resource expansion, and inspire other alliance partners to proactively engage in $\mathrm{R} \& \mathrm{D}$ ventures. Besides, the central organization's visible reputation can be collectively evaluated. Such an organization can make better partner choices and set up more stable cooperative partnerships than the organizations at the edge of R\&D alliance networks [64].

Our study posits that the different levels of degree centrality change the effect that the knowledge diversity has on the innovation capability. That is, the high level of degree centrality might make up for the shortcomings of excessive diverse knowledge elements that weaken innovation outcomes because a high degree centrality can support more stable long-term cooperation relationships and frequent information exchanging [64]. According to resource 
dependency theory [65], the aim for the establishment of alliances between organizations is that they depend on mutually unique resources. Organizations at the center of networks occupy richer resources than other organizations at the edge of networks [29]. Participants establish direct cooperative relationships with central organizations, which means they have a strong dependence on the central organizations' resources and implies a more stable and intensive cooperative relationship with the central organization than those at the edge of networks. In R\&D alliance networks, as an organization's degree centrality gets higher, the increased mutual and frequent communications among alliance partners brought by stable and intensive cooperative relationships can mostly facilitate the organization to combine its diverse knowledge with other alliance partners effectively. Although some small-scale organizations do not have strong cognitive capabilities to integrate overdiversified knowledge [37], a central position within networks can strengthen their recognizing and absorbing capability and promote knowledge transferring effectively. Notably, central organizations typically are the industry leaders, who have strong cognitive capabilities and extensive experiences to bear a high combination cost that is brought by excessive diverse knowledge elements.

With this logic, we further predict that degree centrality can moderate the inverted U-shaped effect of knowledge diversity on organizational innovation capability. That is, when the knowledge diversity is weak, the frequent communication and intensity of knowledge flow created by the high degree centrality enable the participants to share their knowledge in networks. As knowledge diversity increases, it can further benefit from stable cooperation relationships created by the high degree centrality, which would reduce the high cost of those organizations processing overabundant of knowledge elements to combine and integrate new knowledge elements with other organizations.

In summary, as the degree centrality of organizations gets stronger, the benefits from the degree centrality tend to be increased, making the curve of inverted U-shaped effect of knowledge diversity on the organizational innovation capability weaker. Overall, our study poses this hypothesis:

Hypothesis 6. Degree centrality plays a moderating role in the relationship between knowledge diversity and organizational innovation capability.

\subsubsection{Knowledge Proximity and Degree Centrality.} Knowledge proximity can be defined as the extent of cognitive proximity among cooperators [66]. In our study, knowledge proximity is measured by the degree to which two organizations are connected to same knowledge elements in their interorganizational knowledge network [17]. The effect of knowledge proximity on innovation capability is a much-debated topic in previous research.

Based on the absorptive capacity theory, connecting proximity knowledge elements could stimulate the communication between alliance partners because they have similar technology cognition $[67,68]$. Thus, the cooperation costs are lower, and knowledge sharing and transferring are more efficient [17]. Besides, previous research studies have demonstrated that organizations can make it easier to absorb new technologies from their alliance partners through knowledge sharing when they have proximity knowledge bases, which can be a precondition for generating innovativeness $[69,70]$. Based on the resource-based view theory, the mutual incentive to collaborate is decided by the resource complementarity [71]. Organizations search for technology partners who are faced with a trade-off of resource complementarity; thus, a common knowledge base increases the possibility and willingness to cooperate. Moreover, a high level of knowledge proximity helps alliance partners reduce communication costs, consequently weakening risks of confusion and misunderstanding [72]. Thus, knowledge proximity promotes knowledge sharing and increases the possibilities of recombining mutual knowledge elements into innovations.

However, knowledge proximity is not always beneficial for innovation. With the knowledge proximity among organizations increasing, the influence on new combinations may reduce or even turn negative. Crescenzi et al. argued that extreme proximity might lead to a lock-in effect, and redundant common knowledge in alliance knowledge bases might restrain innovation [66]. When the knowledge elements among alliance partners are homogenesis, organizations may face searching barriers and limiting potential recombination scope. Recombination requires seeking new interdependencies among different knowledge elements [73]. The homogenesis knowledge bases may restrict cooperative organizations' conceptual capabilities and raise the challenges of generating new combinations. Besides, new recombination frequently comes from different technological areas. As knowledge proximity surpasses a specific value, the effectiveness of utilizing cooperation for innovative combination will vanish, owing to the declined diverse knowledge elements. Therefore, in the recombination practice, organizations should have certain homogenesis knowledge bases to fully absorb the knowledge shared by collaboration partners, but unique and diverse knowledge is significant to support novel recombination.

Therefore, our research posits an inverted U-shaped relationship between knowledge proximity and organizational innovation capability. That is, when the number of an organization's proximity knowledge with other alliance partners is lower, the organizational innovation capability may suffer from lacking common knowledge bases, thus increasing the difficulty of integration. As its proximity increases, the enhanced common knowledge bases among alliance partners will reduce the cost of new knowledge combinations and improve innovation capability. However, such enhanced proximity knowledge bases will also decline the innovation activities of alliances. When the proximity knowledge is possessed too much, the benefits from knowledge combination and sharing will reduce. Thus, we propose this hypothesis:

Hypothesis 7. Knowledge proximity has an inverted U-shaped effect on organizational innovation capability. 
Moreover, organizations with a central position within R\&D alliance networks might affect the relationship between knowledge proximity and organizational innovation capability. Gilsing et al. [74] showed that degree centrality plays a critical role in searching for novel combinations. Organizations with a higher degree centrality can better familiarize what is going on in their alliance networks, which might increase the possibilities of combining innovative knowledge elements [75]. Besides, as a resource controller in R\&D alliance networks, the higher status and power to control knowledge resources would increase the bargaining power [76] and bring diverse knowledge elements for organizations with overproximity knowledge bases with their alliance partners.

Therefore, our study posits that the different levels of degree centrality change the effect that the knowledge proximity has on the innovation capability. That is, the high level of degree centrality of organizations might make up for the shortcomings of overproximity knowledge elements that weaken innovation outcomes because high degree centrality could support rich and diverse knowledge resources for organizations with excessive proximity knowledge bases and promotes new knowledge combinations [74]. Degree centrality is recognized as a source of innovativeness because organizations with a central position have more opportunities to access external diverse information and resources [43]. Besides, an organization with a high degree centrality tends to have more chances to combine new knowledge elements and attract more influential organizations for $\mathrm{R} \& \mathrm{D}$ projects [45] that would bring more diverse and specialized knowledge elements for central organizations to develop new combinations and enhance innovation capability.

On this logic, we further predict that degree centrality can moderate the inverted U-shaped effect of the knowledge proximity on the organizational innovation capability. That is, when the amount of proximity knowledge is too low between an organization with its alliance partners, it may lack a common knowledge base to develop new combinations $[69,70]$. However, if the organization has a central position in alliance networks, the frequent communications created by the high degree centrality would promote new combination generation even though it has a lower level of knowledge proximity with its alliance partners. Furthermore, eventhough an organization has high proximity knowledge elements with its alliance partners, it still could generate new combinations because rich resources and information brought by the high degree centrality might weaken the lock-in effect. In this case, organizational innovation capability could benefit from diverse knowledge resources brought by the high degree centrality of R\&D alliance networks.

In summary, as the degree centrality gets stronger, the benefits from the degree centrality tend to be increased, making the curve of inverted U-shaped effect of knowledge proximity on the organizational innovation capability weaker. Overall, our study poses this hypothesis:

Hypothesis 8. Degree centrality plays a moderating role in the relationship between knowledge proximity and organizational innovation capability.
Therefore, based on these hypotheses mentioned above, the proposed research model of our study is shown in Figure 3.

\section{Research Design}

3.1. Data Collecting. Our research setting is in Chinese hightech industries, including organizations in the semiconductor devices, aircraft, motor vehicles, communication equipment, and pharmaceutical industries. We chose these high-tech industries for the following reasons. First, these industries experience considerable changes in technology and competition, which results in increasing R\&D alliances' activities. Second, these high-tech industries regularly patent their inventions [8], making it easy to quantify organizational innovation capability.

In this empirical study, we consider many types of cooperators, such as competitors, suppliers, customers, universities, research institutes, and collaborators from different industries. Furthermore, the alliance samples are limited to the large-scale organizations in these high-tech industries since complete and accurate alliance data are easier to access for industry leaders [8, 77]. As the regional release of Chinese alliances news is limited, some are only published in Chinese magazines. Thus, we collected alliance samples by going through many annual reports, Baidu News, corporate websites, and Industry Association Official websites using reptile software. Around 500 annual reports and over 1000 electronic articles and news reports were checked. After data cleaning, sorting, and deleting other types of alliances such as cooperation on marketing and production, the basic research dataset of our paper includes 442 R\&D alliance samples from 2010 to 2015.

Furthermore, alliances generally last for more than one year, but the end date of alliances is rarely released. Therefore, following previous research approaches $[8,10,23]$, our study assumes that the alliance relationship lasts for three years and uses a 3-year time window to observe $R \& D$ alliance networks. Therefore, $R \& D$ alliances in our samples were divided into four time windows (e.g., 2010-2012, 2011-2013, 2012-2014, and 2013-2015). According to previous studies $[6,11]$, in our research, the cliques were extracted from $\mathrm{R} \& \mathrm{D}$ alliance networks by the UCINET 12.0 software (Network $\rightarrow>$ Subgroups $->$ Cliques). Finally, though other dyad ties are eliminated, the final dataset for our study includes $86 \mathrm{R} \& \mathrm{D}$ cliques during the period from 2010 to 2015. Figure 4 presents R\&D alliance networks in these four time windows. It can be seen that the structural components are cliques and that some cohesive subgroups are connecting several cliques.

Following previous researchers $[78,79]$, the knowledge elements (four-digital IPC codes of patents) were collected from the INCOPAT patent database (https://www.incopat. $\mathrm{com} /$ ) that includes information related to technology classes based on the International Patent Classification (IPC) system. The INCOPAT patent database is a Chinese authoritative data source with a global patent database and provides first-rate patent data and a platform for organizations (e.g., companies, universities, and research 


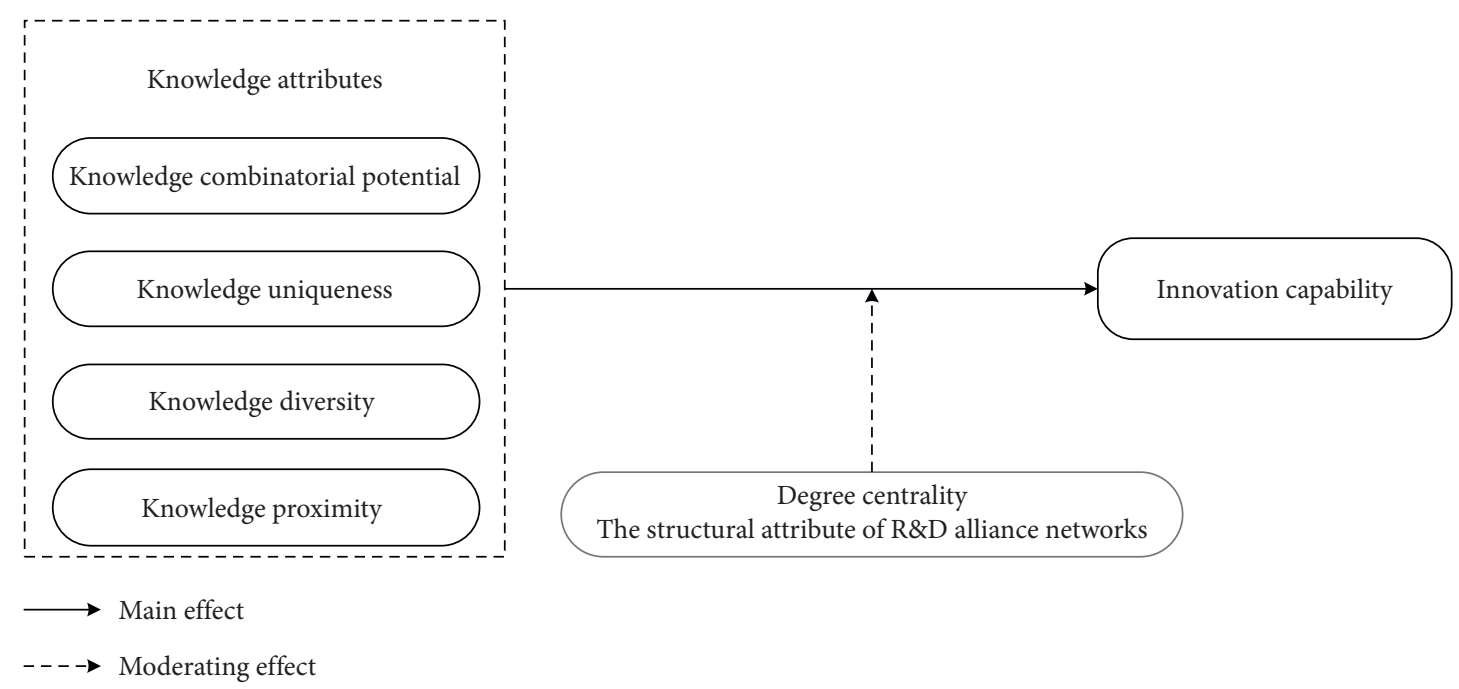

Figure 3: Proposed research model.

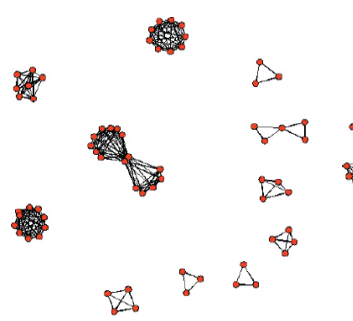

(a)

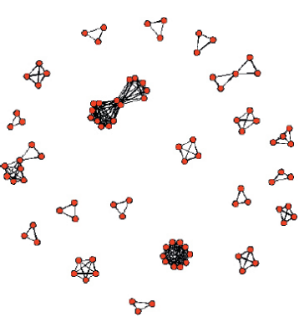

(b)

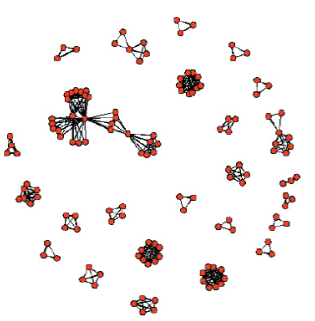

(c)

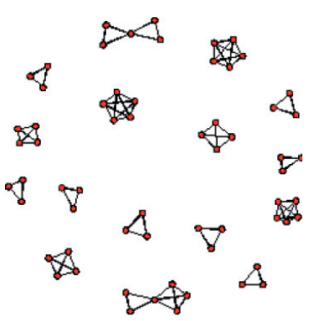

(d)

Figure 4: R\&D alliance networks in five Chinese high-tech industries from 2010 to 2015 (four time windows from left to right). (a) 2010-2012, (b) 2011-2013, (c) 2012-2014, and (d) 2013-2015.

institutions). Drawing on a patent database from one country can ensure conformity, accuracy, and comparability across organizations [79].

\subsection{Variables}

3.2.1. Dependent Variable. Several definitions of innovation capability have been proposed. For Andrea [80], innovation capability refers to organizations' ability to exploit novel products, new processes, and accomplish significant technical and management achievement. Lawson and Samson [81] defined innovation capability as the ability to transfer knowledge into new products for the benefit of organizations. Vicente et al. [82] defined innovation capability as organizations' ability to exploit new products by combining innovative behaviors, strategic capabilities, and internal technical processes. While various definitions of innovation capability have been suggested, our paper will use the definition suggested by Lawson and Samson [81], who saw it as an organization's ability to transfer knowledge and ideas into the new product. For the measurement of innovation capability, the number of patents owned by an organization is a reliable indicator to measure innovation capability in these high-tech industries [8], which can be attributed to the patent that is the explicit knowledge of organizations and the output measure of the innovation capability [83]. In our study, since it frequently takes 2-3 years from patent application to patent authorization, our research adopts the number of granted patents in the third year of participating in alliances to measure the organizational innovation capability. We collected data on granted patents from the INCOPAT patent database.

\subsubsection{Independent Variables from Interorganizational} Knowledge Networks. As shown in our new multilevel network framework (see Figure 2), organizations within R\&D alliance networks are linked to knowledge elements within the interorganizational knowledge network based on their affiliate relationships. Our study uses the connection between organizations and their knowledge elements to acquire information about knowledge attributes.

Following previous researchers $[17,20]$, the knowledge combinatorial potential is measured by the degree centrality of knowledge elements in interorganizational knowledge networks. As shown in Figure 5(a), the more knowledge elements a knowledge element connects, the higher this knowledge element's combinatorial potential. In our research, this variable represents the average degree centrality of an organization's knowledge elements. It can be calculated by two steps: first, computing the degree centrality of 


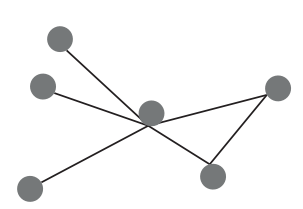

High knowledge combinatorial potential

Knowledge elements

Organizations

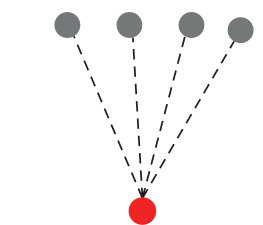

High knowledge diversity $\quad$ Low knowledge diversity

Knowledge elements

Organizations (a)

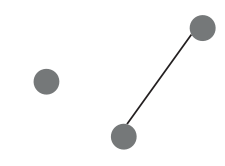

Low knowledge combinatorial potential

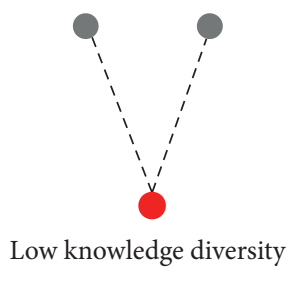

(c)

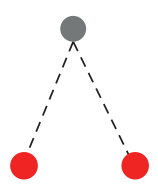

High knowledge uniqueness

Knowledge elements

Organizations

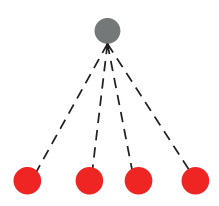

Low knowledge uniqueness

(b)

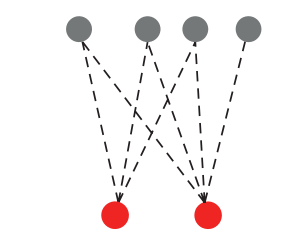

High knowledge proximity

Knowledge elements

Organizations

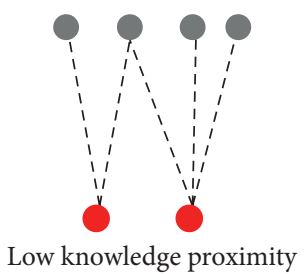

(d)

FIGURE 5: Graph explanation of these four knowledge attributes based on our multilevel network framework of Figure 2: (a) high and low knowledge combinatorial potential; (b) high and low knowledge uniqueness; (c) high and low knowledge diversity; (d) high and low knowledge proximity.

knowledge elements in their interorganizational knowledge networks at each time window, and second, finding out all knowledge elements belonging to each organization and calculating the average value. The formula of knowledge combinatorial potential is

$$
C P_{i}=\operatorname{avg} \sum_{k} \frac{x_{k}}{|N|-1}
$$

where $C P_{i}$ is the average degree centrality of organization $i$ 's knowledge elements, $N$ is the number of knowledge elements in the interorganizational knowledge network $x$, and $x_{k}$ is the number of knowledge elements that knowledge elements $k$ connects directly in its interorganizational knowledge networks $x$.

Knowledge uniqueness can be measured by the number of organizations linked to one knowledge element in twomode networks. Following the previous research method [17], this count is inverted in our model. As shown in Figure 5(b), the fewer the organizations that possess a knowledge element, the more unique it is. This variable represents the average connected number of an organization's knowledge elements, which can be calculated by this formula:

$$
U_{i}=\operatorname{avg} \sum_{k}(-1) a_{k}
$$

where $U_{i}$ is the knowledge uniqueness of organization $i$ and $a_{k}$ is the number of organizations linked to knowledge elements $k$ in the two-mode network $a$.

Knowledge diversity refers to the number of knowledge elements an organization owns [17, 20], which can be calculated as the number of four-digital IPC codes in granted patents of an organization. As shown in Figure 5(c), the more knowledge elements an organization possesses, the more diverse is its knowledge base. It can be calculated by the following formula:

$$
\mathrm{KD}_{i}=\sum_{k} a_{k}
$$

where $K D_{i}$ is the knowledge diversity of organization $i$ and $a_{k}$ is the number of knowledge elements that organization $i$ linked in the two-mode network $a$.

Knowledge proximity can be regarded as the degree to which two organizations are connected to the same knowledge elements in interorganizational knowledge networks [17]. As shown in Figure 5(d), the more knowledge elements that two organizations are similar in their interorganizational knowledge networks, the more the proximity between their knowledge bases. An organization's knowledge proximity is obtained by the percentage of common knowledge elements with its alliance partners and all knowledge elements in its interorganizational knowledge network. This variable represents the average proximity of an organization's knowledge bases with its alliance partners in their interorganizational knowledge network. It can be calculated by this formula:

$$
P_{i}=\operatorname{avg} \sum_{j} \frac{e_{i j}}{k},
$$

where $P_{i}$ refers to the knowledge proximity of organization $i$ with its partners, $e_{i j}$ represents the number of co-possessed 
knowledge elements between organization $i$ and its alliance partner $j$, and $k$ is the sum of knowledge elements in the interorganizational knowledge network.

\subsubsection{A Moderating Variable from Research and Develop-} ment Alliance Networks. Degree centrality (DC) is one of the vital structural indicators used to describe the network position [22]. The high degree centrality reflects the central position of an organization in alliance networks. In our research, degree centrality is calculated by the UCINET 12.0 software $[84,85]$. The formula of degree centrality is

$$
D C_{\text {deg }}(v)=\frac{d_{v}}{|N|-1},
$$

where $D C_{\mathrm{deg}}(v)$ is the organization $v$ 's degree centrality, $N$ is the number of alliance players in organization $v$ 's ego network, and $d_{v}$ is the number of alliance partners that organization $v$ connects directly in its $\mathrm{R} \& \mathrm{D}$ alliance network.

3.2.4. Control Variables. Our study added several control variables regarding the attributes of $\mathrm{R} \& \mathrm{D}$ alliance networks, knowledge, and organizations in our research model, and most of them have shown an effect on innovation capability in previous research.

Control variables at the R\&D alliance network level: some structural attributes of R\&D alliance networks have been shown to influence the dependent variable. Therefore, to specify the effects on the organizational innovation capability, we controlled two structural attributes of R\&D alliance networks, which were calculated by the UCINET 12.0 software. Closeness centrality is defined as the extent to which an actor is far from other actors. Whoever has higher closeness centrality can efficiently communicate with others in networks $[84,86]$, thus yielding a greater probability of innovation output [87]. Closeness centrality is calculated as the sum of the paths from one alliance participant to all other participants in networks. The smaller the sum of paths, the shorter the path from one participant to all other participants in networks and the closer the participant is to all other participants. The sum of the shortest paths between one participant and other participants, after normalization, is a value between $(0,1)$. The larger the value, the higher the closeness of the participant to the center position in networks. Besides, when the numerator in the formula tends to infinity $\infty$, the value of closeness centrality tends to 0 . Therefore, when an organization is very far away from all other organizations in R\&D alliance networks, it is not at the center position, and its closeness centrality tends to 0 . The formula of closeness centrality is

$$
C(x)=\frac{1}{\sum_{y} d(y, x)},
$$

where $C(x)$ is the organization $x$ 's closeness centrality and $\sum_{y} d(y, x)$ is the sum of the distances from organization $x$ to all other partners in its R\&D alliance network. Betweenness centrality measures how frequently an organization lies along the shortest path between two other alliance partners [84]. If the value of an organization's betweenness centrality is 0 , it means that it is located at the edge of R\&D alliance networks and cannot control any alliance partners; if the value is equal to 1 , it means the organization can completely control other alliance partners and possess enormous control power. Besides, the greater the betweenness centrality is for a participant, the greater the opportunities it gets to promote knowledge flow and the greater is its innovation capability $[88,89]$. The formula of betweenness centrality is

$$
b c_{k}=\sum_{i, j} \frac{g_{i k j}}{g_{i j}},
$$

where $b c_{k}$ is the organization $k$ 's betweenness centrality, $g_{i j}$ is the number of paths from organization $i$ to organization $j$ in R\&D alliance networks, and $g_{i k j}$ is the number of those paths that pass through organization $k$ in $\mathrm{R} \& \mathrm{D}$ alliance networks.

Control variables at the knowledge level: presample patent number refers to knowledge accumulation before organizations engaged in alliances [90, 91], and organizational knowledge assets are key organizational factors responsible for innovation [92]. Following Guan et al. [91], the presample patent number is measured as the number of granted patents owned by organizations in the five years before joining its alliances. Cite patent refers to the number of patents that an organization cites from other organizations. This variable reflects the knowledge flow between organizations, which has been demonstrated to influence innovation capability [93]. These patent data were collected from the INCOPAT patent database.

Control variables at the organization level: we collected a set of organizational attributes from annual reports and corporation websites that might influence innovation outcomes. Organization age is regarded as the organizations' history from the establishment to the year of joining alliances. As organizations age, they tend to focus on their existing knowledge bases rather than search for new and unfamiliar knowledge [8], which might influence innovation outcomes. Organizations from different industries might have different innovation capabilities. Based on the International Standard Industrial Classification of All Economic Activities (ISIC), the industry is coded as a five-level variable $(1=$ semiconductor device manufacture (ISIC 3562), 2 = aircraft manufacture (ISIC 374), 3 = motor vehicles manufacture (ISIC 36), 4 = communication equipment manufacture (ISIC 392), and 5=pharmaceutical manufacture (ISIC 27)). Region refers to the geographical location of organizations. In China, organizations located in different areas may have a distinct innovation capability relating to the influence of national policy and geographical environment. Since most of the organizations in our samples are from China, according to the Chinese Geographical Division, it can be regarded as an eightlevel variable $(1=$ Northeast region, $2=$ East China region, $3=$ North China region, $4=$ Central China region, $5=$ South China region, $6=$ Southwest region, $7=$ Northwest region, and $8=$ organizations from other countries).

3.3. Research Approach. As shown in Table 1, the dependent variable, innovation capability, is a count variable. Since the variance of innovation capability (4210.67) is higher than its 


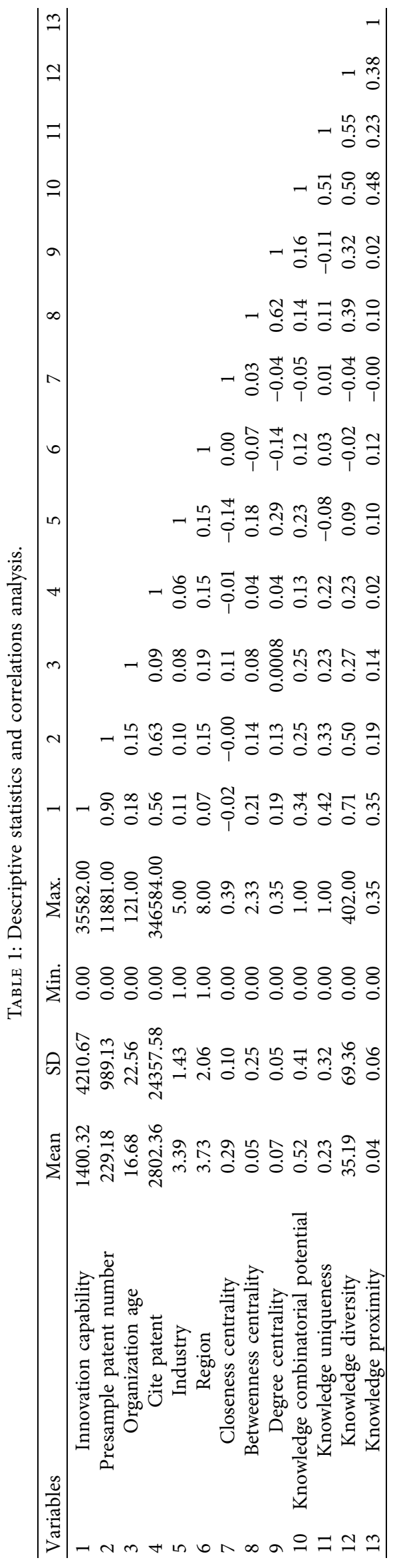


mean (1400.32), the negative binomial regression is adopted to analyze the unbalanced panel data [20]. Furthermore, the Hausman test [89] was employed to choose the fixed or random effects' model. Generally, the random effect model is accepted at the level of $p>0.05$, and if $p<0.05$, the fixed effect model is chosen. Moreover, correlation levels between variables (except dependent variables) are low, no more than 0.7 , which excludes the possibility of multicollinearity.

\section{Results}

Tables 2 and 3 present the negative binomial regression results. Model 1 displays a basic model that tests all the control variables. Models 2-7 add independent variables related to knowledge attributes to the basic Model 1, separately. Models $8-11$ add the moderating variable related to structural attributes of $\mathrm{R} \& \mathrm{D}$ alliance networks to the basic Model 1, respectively. Hypothesis 1 forecasts that the knowledge combinatorial potential facilitates organizational innovation capability. Model 2 in Table 2 shows a positive significant effect at the level of $p<0.001$; thus, Hypothesis 1 is supported. The result indicates that organizations can benefit more from an increasing combinatorial potential of knowledge elements. However, Hypothesis 2 is not supported because there is no significant interaction effect between degree centrality and knowledge combinatorial potential (see Model 8 in Table 3).

Hypothesis 3 predicts that knowledge uniqueness has an inverted U-shaped effect on organizational innovation capability. Model 3 in Table 2 provides statistical support for the hypothesis. As shown in Model 3, knowledge uniqueness has a positive effect on innovation capability $(\beta=8.203$ and $p<0.001$ ), while knowledge uniqueness square has a significant negative effect on innovation capability $(\beta=-6.807$ and $p<0.001)$. Besides, our study tested the cubic of the variables further, and surprisingly, knowledge uniqueness cubic has a significant positive effect on innovation capability $(\beta=8.252$ and $p<0.05)$ (see Model 4 in Table 2 ), which presents a nonlinear relationship. However, as shown in Figure 6, as the number of unique knowledge elements increases, it results in increasing of marginal returns in the early stage and slowly diminishing of marginal returns later. Therefore, Hypothesis 3 is partially supported. Hypothesis 4 forecasts that the degree centrality plays a moderating role in the relationship between knowledge uniqueness and organizational innovation capability. Model 9 in Table 3 shows a nonsignificant intereffect. Therefore, Hypothesis 4 is not supported.

Hypothesis 5 predicts that knowledge diversity has an inverted U-shaped relationship with organizational innovation capability. Model 5 in Table 2 provides statistical support for the hypothesis. That is, as shown in Model 5, knowledge diversity is positively related to its innovation capability $(\beta=0.0349$ and $p<0.001)$, while the knowledge diversity square has a significant negative effect on innovation capability $(\beta=-0.0000638$ and $p<0.001)$. Besides, the results of the knowledge diversity cubic do not show in Table 2 because it is not significant. Therefore, with the diversified knowledge elements' overgrowth, the positive effect on innovation capability tends to reduce gradually (see Figure 7, the original curve). Hypothesis 6 forecasts that degree centrality plays a moderating role in the relationship between knowledge diversity and organizational innovation capability. Model 10 in Table 3 supports the hypothesis at a significant level of $p<0.001$. Figure 7 presents an overview of the intereffect between knowledge diversity and degree centrality in three levels (high degree centrality, medium degree centrality, and low degree centrality), which shows that the inverted U-shaped effect of knowledge diversity on innovation capability is weaker for organizations with a high degree centrality in R\&D alliance networks.

Hypothesis 7 forecasts that knowledge proximity has an inverted U-shaped effect on organizational innovation capability. As shown in Model 6, knowledge proximity is positively related to its innovation capability $(\beta=26.75$ and $p<0.001$ ), while knowledge proximity square presents a significant negative effect on innovation capability $(\beta=-73.83$ and $p<0.001)$. Besides, we tested the cubic of the variables further, and surprisingly, knowledge proximity cubic has a significant positive effect on innovation capability $(\beta=488.5$ and $p<0.001$ ) (see Model 7 in Table 2$)$. It indicates that knowledge proximity shows an inverted S-shaped effect on innovation capability. Therefore, Hypothesis 7 is not supported. As shown in Figure 8, with the degree of knowledge proximity enhancing, it results in increasing of marginal returns in the early stage, sharply diminishing of marginal returns in the middle stage, and increasing of marginal returns in the later stage again. Hypothesis 8 predicts that degree centrality plays a moderating role in the relationship between knowledge proximity and organizational innovation capability. The result of Model 11 in Table 3 does not support this hypothesis.

\section{Discussion and Conclusion}

5.1. Discussion. Knowledge is a valued treasure and an essential resource for organizations. In our paper, the interorganizational knowledge bases are conceptualized as knowledge networks, and we investigated how knowledge attributes affect innovation capability. Besides, our research investigated one structural attribute of $R \& D$ alliance networks (degree centrality) and tested its interaction effects with the knowledge attributes of interorganizational knowledge networks in five Chinese high-tech industries based on the multilevel network approach.

The current study found that organizations with higher combinatorial potential in interorganizational knowledge networks can positively influence innovation outcomes. The result indicates that organizations with the high knowledge combinatorial potential have a higher opportunity to integrate and absorb diverse knowledge from their alliance partners. This finding is consistent with Brennecke and Rank [17], who found that inventors are dependent on the degree centrality of knowledge elements as the essential standard for inventive probabilities. In other words, high knowledge combinatorial potential plays a critical role in the innovation generation. However, this result differs from that of Wang et al. [20], who demonstrated that the average degree 
TABLE 2: Negative binomial analysis of knowledge attributes and organizational innovation capability.

\begin{tabular}{|c|c|c|c|c|c|c|c|}
\hline Variables & Model 1 & Model 2 & Model 3 & Model 4 & Model 5 & Model 6 & Model 7 \\
\hline \multicolumn{8}{|l|}{ Control variables } \\
\hline Presample patent number & $\begin{array}{l}0.000436^{* * *} \\
\quad(11.32)\end{array}$ & $\begin{array}{l}0.000386^{* * *} \\
(12.20)\end{array}$ & $\begin{array}{l}0.000336^{* * *} \\
(5.79)\end{array}$ & $\begin{array}{l}0.000333^{* * *} \\
(5.85)\end{array}$ & $\begin{array}{l}0.000118^{*} \\
\quad(2.25)\end{array}$ & $\begin{array}{l}0.000517^{* * *} \\
(14.91)\end{array}$ & $\begin{array}{l}0.000537^{* * *} \\
(15.59)\end{array}$ \\
\hline Organization age & $\begin{array}{l}0.0126^{* * *} \\
(5.37)\end{array}$ & $\begin{array}{c}0.00378 \\
(1.61)\end{array}$ & $\begin{array}{l}0.00814^{* *} \\
(2.79)\end{array}$ & $\begin{array}{l}0.00819^{* *} \\
(2.74)\end{array}$ & $\begin{array}{c}0.00174 \\
(0.89)\end{array}$ & $\begin{array}{c}0.0107^{* * *} \\
(4.88)\end{array}$ & $\begin{array}{l}0.00982^{* * *} \\
\quad(4.53)\end{array}$ \\
\hline Cite patent & $\begin{array}{c}0.00000310 \\
(1.95)\end{array}$ & $\begin{array}{c}0.00000321^{*} \\
(2.28)\end{array}$ & $\begin{array}{c}0.00000813^{* * *} \\
(3.99)\end{array}$ & $\begin{array}{c}0.00000793^{* * *} \\
(3.95)\end{array}$ & $\begin{array}{c}0.00000349 \\
(1.69)\end{array}$ & $\begin{array}{c}0.00000514^{* * *} \\
(3.35)\end{array}$ & $\begin{array}{c}0.00000557^{* * *} \\
(3.62)\end{array}$ \\
\hline Industry & $\begin{array}{c}0.0303 \\
(0.71)\end{array}$ & $\begin{array}{c}-0.141^{* *} \\
(-3.26)\end{array}$ & $\begin{array}{c}0.248^{* * *} \\
(4.36)\end{array}$ & $\begin{array}{c}0.250^{* * *} \\
(4.42)\end{array}$ & $\begin{array}{l}0.101 \\
(1.93)\end{array}$ & $\begin{array}{c}-0.0418 \\
(-1.03)\end{array}$ & $\begin{array}{c}-0.0403 \\
(-0.99)\end{array}$ \\
\hline Region & $\begin{array}{c}-0.00511 \\
(-0.17)\end{array}$ & $\begin{array}{c}-0.0183 \\
(-0.63)\end{array}$ & $\begin{array}{c}-0.0354 \\
(-0.96)\end{array}$ & $\begin{array}{c}-0.0416 \\
(-1.13)\end{array}$ & $\begin{array}{l}0.0667 \\
(1.79)\end{array}$ & $\begin{array}{c}-0.0853^{* *} \\
(-2.92)\end{array}$ & $\begin{array}{c}-0.0841^{* *} \\
(-2.92)\end{array}$ \\
\hline Closeness centrality & $\begin{array}{l}-1.120 \\
(-1.81)\end{array}$ & $\begin{array}{l}-0.411 \\
(-0.70)\end{array}$ & $\begin{array}{l}1.253 \\
(1.62)\end{array}$ & $\begin{array}{l}1.123 \\
(1.42)\end{array}$ & $\begin{array}{l}-0.500 \\
(-0.69)\end{array}$ & $\begin{array}{l}-0.583 \\
(-0.99)\end{array}$ & $\begin{array}{l}-1.160^{*} \\
(-2.03)\end{array}$ \\
\hline Betweenness centrality & $\begin{array}{c}0.853^{* * *} \\
(4.59) \\
\end{array}$ & $\begin{array}{c}0.841^{* * *} \\
(5.97)\end{array}$ & $\begin{array}{l}0.457 \\
(1.92) \\
\end{array}$ & $\begin{array}{l}0.410 \\
(1.73) \\
\end{array}$ & $\begin{array}{c}-0.0306 \\
(-0.20) \\
\end{array}$ & $\begin{array}{c}0.834^{* * *} \\
(4.92) \\
\end{array}$ & $\begin{array}{c}0.813^{* * *} \\
(4.69) \\
\end{array}$ \\
\hline $\begin{array}{l}\text { Independent variables } \\
\text { Knowledge combinatorial } \\
\text { potential }\end{array}$ & & $\begin{array}{c}2.746^{* * *} \\
(15.25)\end{array}$ & & & & & \\
\hline Knowledge uniqueness & & & $\begin{array}{c}8.203^{* * *} \\
(10.75)\end{array}$ & $\begin{array}{c}11.81^{* * *} \\
(7.15)\end{array}$ & & & \\
\hline Knowledge uniqueness ${ }^{2}$ & & & $\begin{array}{c}-6.807^{* * *} \\
(-8.62)\end{array}$ & $\begin{array}{c}-18.38^{* * *} \\
(-3.81)\end{array}$ & & & \\
\hline Knowledge uniqueness $^{3}$ & & & & $\begin{array}{l}8.252^{*} \\
(2.42)\end{array}$ & & & \\
\hline Knowledge diversity & & & & & $\begin{array}{c}0.0349^{* * *} \\
(18.13)\end{array}$ & & \\
\hline Knowledge diversity $^{2}$ & & & & & $\begin{array}{c}-0.0000638^{* * *} \\
(-11.36)\end{array}$ & & \\
\hline Knowledge proximity & & & & & & $\begin{array}{c}26.75^{* * *} \\
(10.35)\end{array}$ & $\begin{array}{c}46.21^{* * *} \\
(11.35)\end{array}$ \\
\hline Knowledge proximity $^{2}$ & & & & & & $\begin{array}{c}-73.83^{* * *} \\
(-5.57)\end{array}$ & $\begin{array}{c}-282.5^{* * *} \\
(-7.17)\end{array}$ \\
\hline Knowledge proximity ${ }^{3}$ & & & & & & & $\begin{array}{c}488.5^{* * *} \\
(5.72)\end{array}$ \\
\hline Constant & $\begin{array}{c}-1.725^{* * *} \\
(-6.55)\end{array}$ & $\begin{array}{c}-2.327^{* * *} \\
(-9.14)\end{array}$ & $\begin{array}{l}3.460^{* * *} \\
(9.05)\end{array}$ & $\begin{array}{l}3.495^{* * *} \\
(9.05)\end{array}$ & $\begin{array}{c}-2.249^{* * *} \\
(-6.23)\end{array}$ & $\begin{array}{c}-1.680^{* * *} \\
(-6.70)\end{array}$ & $\begin{array}{c}-1.636^{* * *} \\
(-6.73)\end{array}$ \\
\hline $\begin{array}{l}\text { Log likelihood } \\
\text { Hausman test }\end{array}$ & -2232.5325 & -2096.8939 & -1023.5422 & -1020.5709 & -997.10765 & -2140.6111 & -2123.298 \\
\hline Wald chi2 & 6.65 & 14.41 & 14.84 & 16.49 & 0.00 & -1.08 & 5.41 \\
\hline Prob $>$ chi2 & 0.2553 & 0.0253 & 0.0382 & 0.0359 & 0.00 & 0.00 & 0.6100 \\
\hline
\end{tabular}

Notes: observations $=381 ; z$ value in parentheses, ${ }^{*}$ means $p<0.05,{ }^{* *}$ means $p<0.01$, and ${ }^{* * *}$ means $p<0.001$.

centrality of knowledge elements in knowledge networks has an inverted U-shaped relationship with exploratory innovation. A possible reason is that the dependent variable (the number of granted patents) in our research differs from exploratory innovation (the number of new knowledge elements explored by inventors). Concerning knowledge uniqueness, our study found that organizations with an excessive number of unique knowledge elements could hinder their innovation process. These results mirror previous studies that organizations possessing a large unique knowledge stock might decrease external exploitation and less actively search for new ideas from their alliance partners $[33,49]$.

Regarding knowledge diversity, results show that organizations cannot benefit more from overdiversified knowledge bases. These results are consistent with the findings of previous researchers that suggested that, as diversified knowledge elements increase, the technological distance becomes larger in knowledge networks, which may weaken organizational recognizing and absorbing capability $[35,61]$. Moreover, previous researchers argue that knowledge networks and collaboration networks among inventors are decoupled $[14,20]$. Our research found that they are slightly inter-act simultaneously after integrating studies of R\&D alliance networks and their interorganizational knowledge networks. These results are similar to Brennecke and Rank [17], who found an interaction effect between knowledge networks and social networks among inventors. However, the distinct difference from previous research is that ours focuses on the interorganizational networks rather than the social networks in intraorganization. Our analysis of the interaction effects shows 
TABLE 3: Negative binomial analysis of the interaction effect between knowledge attributes and degree centrality.

\begin{tabular}{|c|c|c|c|c|}
\hline Variables & Model 8 & Model 9 & Model 10 & Model 11 \\
\hline \multicolumn{5}{|l|}{ Control variables } \\
\hline Presample patent number & $\begin{array}{l}0.000386^{* * *} \\
\quad(12.20)\end{array}$ & $\begin{array}{l}0.000318^{* * *} \\
\quad(5.78)\end{array}$ & $\begin{array}{l}0.000122^{* *} \\
\quad(2.62)\end{array}$ & $\begin{array}{l}0.000527^{* * *} \\
(14.72)\end{array}$ \\
\hline Organization age & $\begin{array}{c}0.00386^{* * *} \\
(1.63)\end{array}$ & $\begin{array}{c}0.00616^{*} \\
(2.10)\end{array}$ & $\begin{array}{c}0.00257 \\
(1.38)\end{array}$ & $\begin{array}{l}0.0102^{* * *} \\
\quad(4.62)\end{array}$ \\
\hline Cite patent & $\begin{array}{c}0.00000319^{*} \\
(2.27)\end{array}$ & $\begin{array}{c}0.00000853^{* * *} \\
(4.68)\end{array}$ & $\begin{array}{c}0.00000259 \\
(1.34)\end{array}$ & $\begin{array}{c}0.00000557^{* * *} \\
(3.61)\end{array}$ \\
\hline Industry & $\begin{array}{c}-0.143^{*} \\
(-3.21)\end{array}$ & $\begin{array}{l}0.144^{*} \\
(2.51)\end{array}$ & $\begin{array}{l}0.112^{*} \\
(2.13)\end{array}$ & $\begin{array}{c}-0.0642 \\
(-1.49)\end{array}$ \\
\hline Region & $\begin{array}{c}-0.0176 \\
(-0.59)\end{array}$ & $\begin{array}{c}0.0155 \\
(0.41)\end{array}$ & $\begin{array}{c}0.0403 \\
(1.05)\end{array}$ & $\begin{array}{c}-0.0750^{*} \\
(-2.56)\end{array}$ \\
\hline Closeness centrality & $\begin{array}{l}-0.442 \\
(-0.73)\end{array}$ & $\begin{array}{l}-0.109 \\
(-0.13)\end{array}$ & $\begin{array}{c}-1.879^{*} \\
(-2.50)\end{array}$ & $\begin{array}{c}-1.366^{*} \\
(-2.35)\end{array}$ \\
\hline Betweenness centrality & $\begin{array}{c}0.796^{* * *} \\
(3.37) \\
\end{array}$ & $\begin{array}{r}0.254 \\
(0.73) \\
\end{array}$ & $\begin{array}{l}0.452 \\
(1.65) \\
\end{array}$ & $\begin{array}{l}0.514^{*} \\
(2.08) \\
\end{array}$ \\
\hline \multicolumn{5}{|l|}{ Independent variables } \\
\hline Knowledge combinatorial potential & $\begin{array}{c}2.703^{* * *} \\
(8.99)\end{array}$ & & & \\
\hline Knowledge uniqueness & & $\begin{array}{c}8.338^{* *} \\
(2.84)\end{array}$ & & \\
\hline Knowledge uniqueness ${ }^{2}$ & & $\begin{array}{l}-10.07 \\
(-1.22)\end{array}$ & & \\
\hline Knowledge uniqueness $^{3}$ & & $\begin{array}{l}3.965 \\
(0.70)\end{array}$ & & \\
\hline Knowledge diversity & & & $\begin{array}{c}0.0510^{* * *} \\
(15.30)\end{array}$ & \\
\hline Knowledge diversity ${ }^{2}$ & & & $\begin{array}{c}-0.000138^{* * *} \\
(-10.10)\end{array}$ & \\
\hline Knowledge proximity & & & & $\begin{array}{c}45.23^{* * *} \\
(6.35)\end{array}$ \\
\hline Knowledge proximity $^{2}$ & & & & $\begin{array}{c}-267.5^{* * *} \\
(-3.73)\end{array}$ \\
\hline Knowledge proximity ${ }^{3}$ & & & & $\begin{array}{c}416.6^{* *} \\
(2.57) \\
\end{array}$ \\
\hline \multicolumn{5}{|l|}{ The moderating variable } \\
\hline Degree centrality (DC) & $\begin{array}{l}-0.177 \\
(-0.06) \\
\end{array}$ & $\begin{array}{l}6.101^{*} \\
(2.33) \\
\end{array}$ & $\begin{array}{l}0.574 \\
(0.28) \\
\end{array}$ & $\begin{array}{r}2.240^{*} \\
(1.09) \\
\end{array}$ \\
\hline \multicolumn{5}{|l|}{ Interaction effects } \\
\hline Knowledge combinatorial potential $\times \mathrm{DC}$ & $\begin{array}{l}0.592 \\
(0.17)\end{array}$ & & & \\
\hline Knowledge uniqueness $\times$ DC & & $\begin{array}{l}65.68^{*} \\
(1.99)\end{array}$ & & \\
\hline Knowledge uniqueness $^{2} \times \mathrm{DC}$ & & $\begin{array}{l}-127.9 \\
(-1.45)\end{array}$ & & \\
\hline Knowledge uniqueness ${ }^{3} \times \mathrm{DC}$ & & $\begin{array}{l}55.53 \\
(0.93)\end{array}$ & & \\
\hline Knowledge diversity $\times \mathrm{DC}$ & & & $\begin{array}{c}-0.109^{* * *} \\
(-4.20)\end{array}$ & \\
\hline Knowledge diversity $^{2} \times \mathrm{DC}$ & & & $\begin{array}{c}0.000468^{* * *} \\
(5.71)\end{array}$ & \\
\hline Knowledge proximity $\times$ DC & & & & $\begin{array}{l}12.80 \\
(0.13)\end{array}$ \\
\hline Knowledge proximity $^{2} \times \mathrm{DC}$ & & & & $\begin{array}{l}-263.6 \\
(-0.24)\end{array}$ \\
\hline Knowledge proximity ${ }^{3} \times \mathrm{DC}$ & & & & $\begin{array}{l}1536.1 \\
(0.59)\end{array}$ \\
\hline Constant & $\begin{array}{l}-2.302^{* * *} \\
(-7.20)\end{array}$ & $\begin{array}{c}-3.312^{* * *} \\
(-7.94)\end{array}$ & $\begin{array}{l}-1.818^{* * *} \\
(-5.27)\end{array}$ & $\begin{array}{c}-1.681^{* * *} \\
(-6.13)\end{array}$ \\
\hline $\begin{array}{l}\text { Log likelihood } \\
\text { Hausman test }\end{array}$ & -2096.8635 & -1005.4259 & -982.69748 & -2120.7159 \\
\hline Wald chi2 & 15.43 & 152.34 & 28.24 & 18.41 \\
\hline Prob $>$ chi 2 & 0.0513 & 0.00 & 0.0004 & 0.00 \\
\hline
\end{tabular}

Notes: observations $=381 ; z$ value in parentheses, ${ }^{*}$ means $p<0.05,{ }^{* *}$ means $p<0.01$, and ${ }^{* * *}$ means $p<0.001$. 


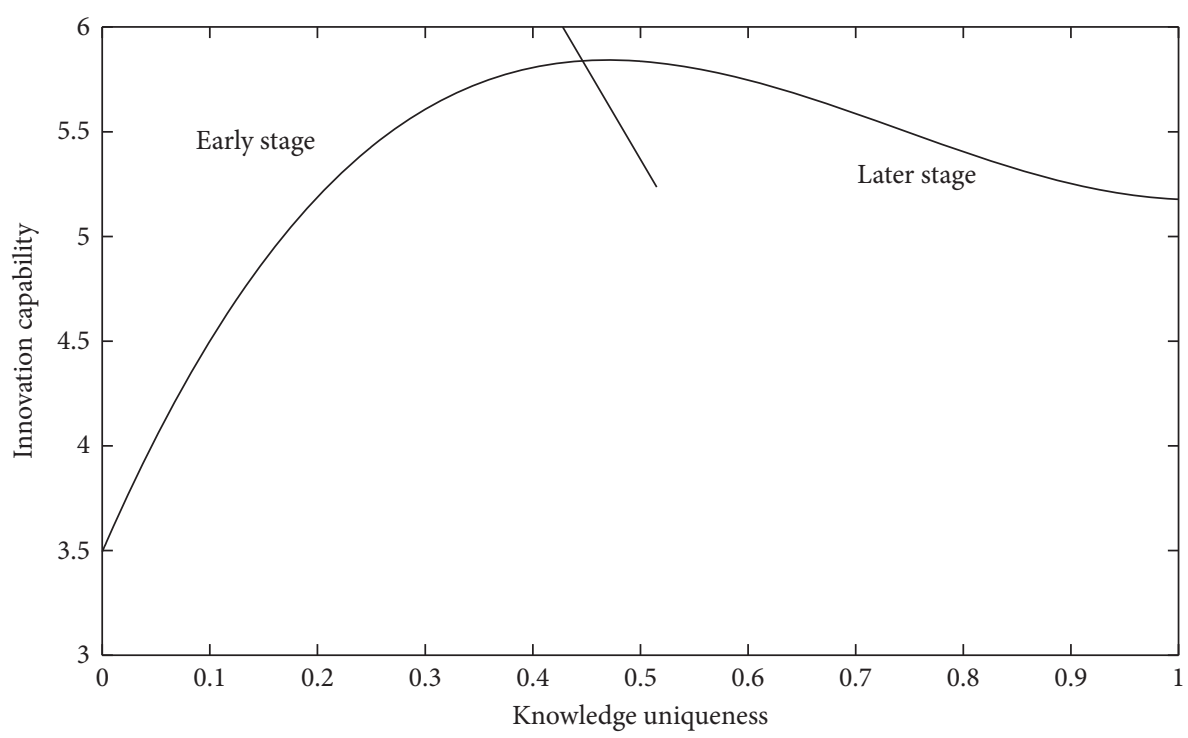

FIGURE 6: Effect of knowledge uniqueness and innovation capability.

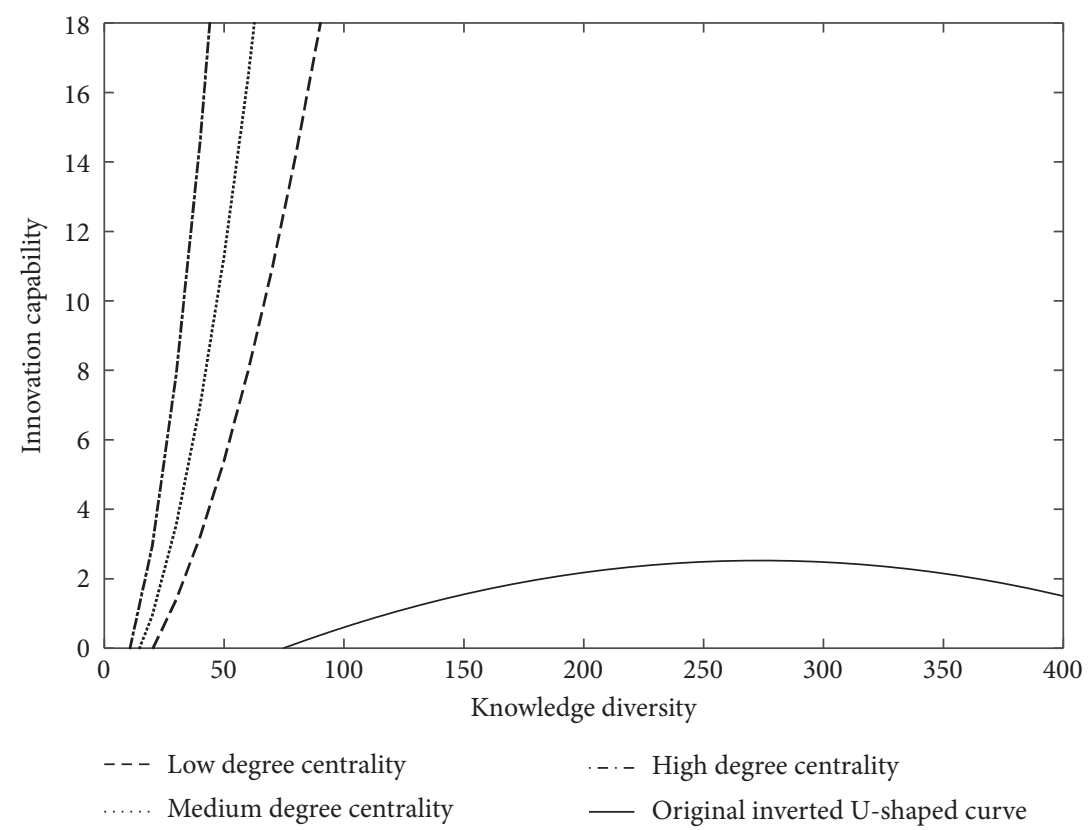

FIGURE 7: Effect of knowledge diversity and interaction effect between knowledge diversity and degree centrality.

that, among four knowledge attributes, organizations with diverse knowledge elements can receive more benefits from higher than from the lower degree centrality, which shows the advantages of high degree centrality in $R \& D$ alliance networks for organizations with overdiversified knowledge elements.

Furthermore, our research found that knowledge proximity has an inverted S-shaped effect on organizational innovation capability. Previous studies found that knowledge proximity facilitates knowledge sharing, exchange, and transfer among organizations [17]. However, in our study, we only find the increasing of marginal revenue in the early stage and later stage, which, to some extent, contradicts the technology lock-in effect $[66,94]$. The possible reasons are as follows. First, when an organization has a low proximity knowledge base with its alliance partners in the early stage, technology complementary would increase the possibility of knowledge combination and enhance innovation capability. Second, at the middle stage, organizations could share part of diverse knowledge with their alliance partners, and the cost of integrating heterogeneous knowledge is still very high, so the marginal revenue turns to dimmish. Third, in the later stage, an organization has a high proximity knowledge base with its alliance partners and shares a common language. Although they only could share limited distinct knowledge, the cost of integrating heterogeneous knowledge is meager, which may increase the marginal revenue gradually. 


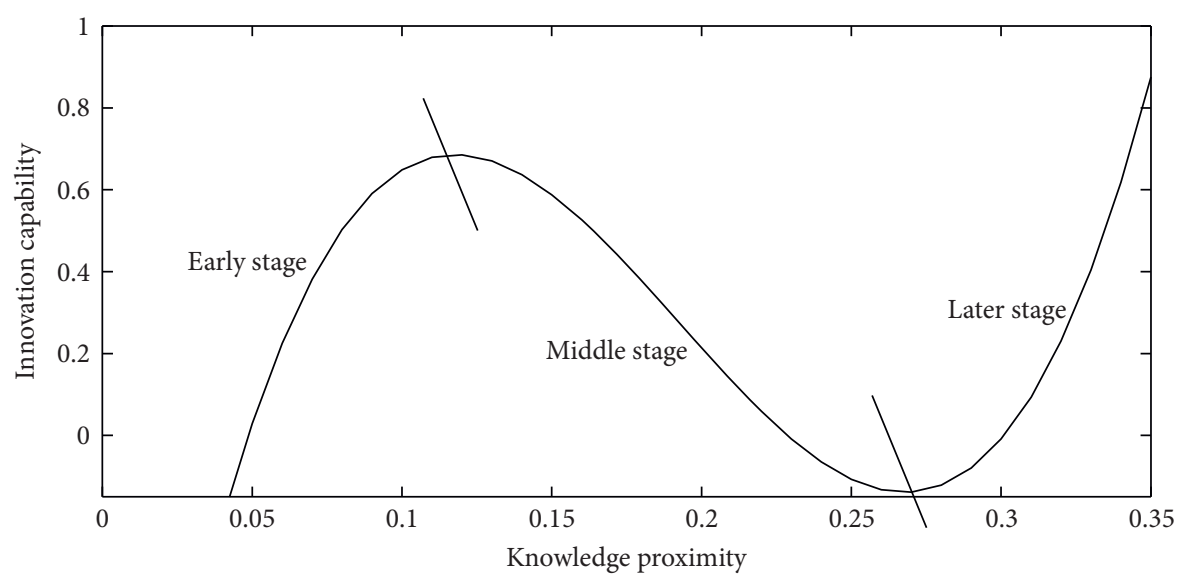

FIGURE 8: Effect of knowledge proximity and innovation capability.

\section{Conclusion}

The purpose of our research is to explore the impact of interorganizational knowledge networks' knowledge attributes on organizational innovation capability and to identify the impact of the interaction effect between R\&D alliance networks and interorganizational knowledge networks on organizational innovation capability. The findings of our study answered the two research questions we proposed. First, different knowledge attributes show a distinct effect on organizational innovation capability, including linear relationship, inverted U-shaped curve relationship, and inverted S-shaped curve relationship. Empirical research results help us better understand how different knowledge attributes influence organizational innovation capability and stimulate interorganizational knowledge generation. Second, prior studies have noted the importance of the interaction effect between two distinct levels of networks in the interorganizational field [14]. We have examined this question further. Our findings show that the central position within R\&D alliance networks finitely moderates the relationship between knowledge attributes of interorganizational knowledge networks and organizational innovation capability.

In the methodology, we introduced the multilevel network approach from the intraorganizational research field to address innovation management issues in the interorganizational field [17, 40, 41]. Only a few empirical studies use this method in the existing literature to analyze the R\&D alliance network, especially for its interorganizational knowledge networks. Following the previous research method, we developed a new multilevel network framework to capture additional knowledge attributes. This approach will prove useful in expanding our understanding of how to integrate alliance networks and their interorganizational knowledge networks.

Our research has two unique contributions to the current study on interorganizational and network theory. First, we employ an interorganizational knowledge network perspective to describe the knowledge bases of alliances. Our study showcases the importance and viability of utilizing a multilevel network framework and advanced network analysis tools to explore the knowledge attributes of interorganizational knowledge networks. Second, above and beyond the traditional focus on alliance network structures, our research investigates the intereffect with the interorganizational knowledge network, which can enrich our understanding of interorganizational knowledge management from a new perspective.

Our findings have several implications for innovation managers. The main pertains to the knowledge management of $\mathrm{R} \& \mathrm{D}$ alliances. First, these results reported above suggest that knowledge combination potential is positively related to organizational innovation capability. Innovation managers should consider carrying out more innovative cooperation activities with their alliance partners. In this way, organizations could enrich their knowledge elements' combinatorial history and enhance the links between knowledge elements, which would lay a solid base for knowledge elements to occupy the central position in interorganizational knowledge networks. Second, another finding suggests that knowledge uniqueness cannot be possessed excessively by organizations because it presents an inverted U-shaped effect on innovation capability. For organizations with an excessive number of unique knowledge elements, they should consider exploring more cross-domain technology integration projects and improving the applicable fields of unique knowledge elements through increasing external exploration and actively searching for new information from their alliance partners. Third, for organizations with redundant knowledge elements, innovation managers can improve the ability to absorb and recognize new knowledge elements through training of R\&D personnel and improving the R\&D system or they can reduce the high cost of innovation activities in the form of R\&D outsourcing, so as to increase the organizations' innovation benefits. Finally, innovation managers should be aware of controlling the degree of proximity knowledge with their alliance partners, avoiding getting stuck in the middle stage. This requires innovation managers to thoroughly measure the closeness of their own organizations' knowledge base to the target cooperators' knowledge bases and then to formulate targeted knowledge combination strategies to 
improve innovation income. For the second broad recommendation, innovation managers should be aware that the interaction of the R\&D alliance network (interorganizational network based on R\&D partnership) and the interorganizational knowledge networks (combination history of organizational or interorganizational knowledge elements) has an impact on the organizational innovation capability. R\&D alliance networks and interorganizational knowledge networks are two different networks, but they inter-act with each other. Organizations located in distinct network positions could affect the effectiveness of their knowledge combination in interorganizational knowledge networks. According to our findings, organizations located in the central position within R\&D alliance networks play a vital role in the relationship between knowledge diversity and organizational innovation capability. The positive influence of an organization with excessively diverse knowledge on innovation capabilities will not diminish when the organization is located in the center position of $R \& D$ alliance networks. Similarly, organizations' knowledge elements with distinct attributes or different locations in interorganizational knowledge networks could affect the organization's choice of its future alliance partners. Overall, our findings could be used to help organizations sort out their knowledge attributes of knowledge bases and come to understand the impact of the interaction between interorganizational knowledge network and $R \& D$ alliance network on the organizational innovation capability and then make a targeted alliance and knowledge management strategy to carry out innovation activities and enhance their innovation capability.

While our research has implications for theory and practice guidance, it is not without limitations. First, although we choose the alliance samples from five high-tech industries in China, our findings cannot be directly generalized to other countries. Nonetheless, the methodology of our study could be replicated in other settings. Second, our research only sets out the construction of interorganizational knowledge networks from explicit knowledge and ignores the essential tacit knowledge transfer between organizations. Our study uses the four-digital IPC code as the knowledge element because it is easy to display and quantify. However, these codes may not adequately present the process and mechanism of knowledge diffusion among organizations. Therefore, researchers are encouraged to expand our construction method of the interorganizational knowledge network in future research.

\section{Data Availability}

The (alliance sample) data used to support the findings of this study have not been made available because the data also forms part of an ongoing project. The (patent) data used to support the findings of this study were supplied by IncoPat patent database (https://www.incopat.com/) under license and so cannot be made freely available. Requests for access to these data should be made to Beijing INCOPAT CO., LTD., (service@incopat.com).

\section{Conflicts of Interest}

The authors declare that they have no conflicts of interest.

\section{Acknowledgments}

This paper was supported by the National Natural Science Foundation of China (71673179): Empirical Research of China on the Coupling of Clique and Knowledge Flow in Alliance Innovation Network Based on the Self-Organization Theory.

\section{References}

[1] U. Ozmel, D. Yavuz, J. J. Reuer, and T. Zenger, "Network prominence, bargaining power, and the allocation of value capturing rights in high-tech alliance contracts," Organization Science, vol. 28, no. 5, pp. 947-964, 2017.

[2] W. W. Powell, K. W. Koput, and L. Smith-Doerr, "Interorganizational collaboration and the locus of innovation: networks of learning in biotechnology," Administrative Science Quarterly, vol. 41, no. 1, pp. 116-145, 1996.

[3] Y. Su and T. Li, "Simulation analysis of knowledge transfer in a knowledge alliance based on a circular surface radiator model," Complexity, vol. 2020, Article ID 4301489, 27 pages, 2020.

[4] C. Tang, "Accessed external knowledge, centrality of intrateam knowledge networks, and R\&D employee creativity," ReD Management, vol. 46, no. S3, pp. 992-1005, 2016.

[5] R. D. Alba, "Taking stock of network analysis: a decade's results," Research in the Sociology of Organizations, vol. 1, pp. 39-74, 1982.

[6] K. G. Provan and J. G. Sebastian, "Research notes. Networks within networks: service link overlap, organizational cliques, and network effectiveness," Academy of Management Journal, vol. 41, no. 4, pp. 453-463, 1998.

[7] G. Ahuja, G. Soda, and A. Zaheer, "The genesis and dynamics of organizational networks," Organization Science, vol. 23, no. 2, pp. 434-448, 2012.

[8] C. C. Phelps, "A longitudinal study of the influence of alliance network structure and composition on firm exploratory innovation," Academy of Management Journal, vol. 53, no. 4, pp. 890-913, 2010.

[9] G. Ahuja, "Collaboration networks, structural holes, and innovation: a longitudinal study," Administrative Science Quarterly, vol. 45, no. 3, pp. 425-455, 2000.

[10] M. A. Schilling and C. C. Phelps, "Interfirm collaboration networks: the impact of large-scale network structure on firm innovation," Management Science, vol. 53, no. 7, pp. 1113-1126, 2007.

[11] T. J. Rowley, H. R. Greve, H. Rao, J. A. C. Baum, and A. V. Shipilov, "Time to break up: social and instrumental antecedents of firm exits from exchange cliques," Academy of Management Journal, vol. 48, no. 3, pp. 499-520, 2005.

[12] D. Qian, O. Yağan, L. Yang, J. Zhang, and K. Xing, "Diffusion of real-time information in overlaying social-physical networks: network coupling and clique structure," Networking Science, vol. 3, no. 1-4, pp. 43-53, 2013.

[13] I. A. Idrees, A. C. Vasconcelos, and D. Ellis, "Clique and elite: inter-organizational knowledge sharing across five star hotels in the Saudi Arabian religious tourism and hospitality industry," Journal of Knowledge Management, vol. 22, no. 6, pp. 1358-1378, 2018.

[14] J. Guan and N. Liu, "Exploitative and exploratory innovations in knowledge network and collaboration network: a patent analysis in the technological field of nano-energy," Research Policy, vol. 45, no. 1, pp. 97-112, 2016. 
[15] K. Okamura and N. S. Vonortas, "European alliance and knowledge Networks1," Technology Analysis \& Strategic Management, vol. 18, no. 5, pp. 535-560, 2006.

[16] R. Huggins, A. Johnston, and P. Thompson, "Network capital, social capital and knowledge flow: how the nature of interorganizational networks impacts on innovation," Industry \& Innovation, vol. 19, no. 3, pp. 203-232, 2012.

[17] J. Brennecke and O. Rank, “The firm's knowledge network and the transfer of advice among corporate inventors-A multilevel network study," Research Policy, vol. 46, no. 4, pp. 768-783, 2017.

[18] C. Su, M. Huang, and N. Contractor, "Understanding the structures, antecedents and outcomes of organisational learning and knowledge transfer: a multi-theoretical and multilevel network analysis," European Journal of International Management, vol. 4, no. 6, pp. 576-601, 2010.

[19] J. Brennecke and O. N. Rank, "The interplay between formal project memberships and informal advice seeking in knowledge-intensive firms: a multilevel network approach," Social Networks, vol. 44, pp. 307-318, 2016.

[20] C. Wang, S. Rodan, M. Fruin, and X. Xu, "Knowledge networks, collaboration networks, and exploratory innovation," Academy of Management Journal, vol. 57, no. 2, pp. 484-514, 2014.

[21] A. Martínez-Noya and R. Narula, "What more can we learn from R\&D alliances? A review and research agenda," $B R Q$ Business Research Quarterly, vol. 21, no. 3, pp. 195-212, 2018.

[22] X. Wang, W. Dolfsma, and H. van der Bij, "Individual performance in a coopetitive R\&D alliance: motivation, opportunity and ability," R\&D Management, vol. 49, no. 5, pp. 762-774, 2019.

[23] R. Katila and G. Ahuja, "Something old, something new: a longitudinal study of search behavior and new product introduction," Academy of Management Journal, vol. 45, no. 6, pp. 1183-1194, 2002.

[24] S. Xu and E. Cavusgil, "Knowledge breadth and depth development through successful R\&D alliance portfolio configuration: an empirical investigation in the pharmaceutical industry," Journal of Business Research, vol. 101, pp. 402-410, 2019.

[25] D. Tojeiro-Rivero and R. Moreno, "Technological cooperation, R\&D outsourcing, and innovation performance at the firm level: the role of the regional context," Research Policy, vol. 48, no. 7, pp. 1798-1808, 2019.

[26] J. Jacob and G. Duysters, "Alliance network configurations and the co-evolution of firms' technology profiles: an analysis of the biopharmaceutical industry," Technological Forecasting and Social Change, vol. 120, pp. 90-102, 2017.

[27] A. G. Karamanos, "Leveraging micro- and macro-structures of embeddedness in alliance networks for exploratory innovation in biotechnology," R\&D Management, vol. 42, no. 1 , pp. 71-89, 2012.

[28] L. Freeman, "Centrality in networks conceptual clarifications," Social Networks, vol. 1, no. 3, pp. 215-239, 1978.

[29] R. S. Burt, Toward a Structural Theory of Action, Academic Press, San Diego, CA, USA, 1982.

[30] A. C. Inkpen and E. W. K. Tsang, "Social capital, networks, and knowledge transfer," Academy of Management Review, vol. 30, no. 1, pp. 146-165, 2005.

[31] J. E. Perry-Smith and C. E. Shalley, "The social side of creativity: a static and dynamic social network perspective," Academy of Management Review, vol. 28, no. 1, pp. 89-106, 2003.
[32] C. Phelps, R. Heidl, and A. Wadhwa, "Knowledge, networks, and knowledge networks," Journal of Management, vol. 38, no. 4, pp. 1115-1166, 2012.

[33] S. Yayavaram and G. Ahuja, "Decomposability in knowledge structures and its impact on the usefulness of inventions and knowledge-base malleability," Administrative Science Quarterly, vol. 53, no. 2, pp. 333-362, 2008.

[34] L. Fleming and O. Sorenson, "Science as a map in technological search," Social Science Electronic Publishing, vol. 25, no. 8/9, pp. 909-928, 2004.

[35] M. L. Weitzman, "Recombinant growth," The Quarterly Journal of Economics, vol. 113, no. 2, pp. 331-360, 1998.

[36] L. Fleming and O. Sorenson, "Technology as a complex adaptive system: evidence from patent data," Research Policy, vol. 30, no. 7, pp. 1019-1039, 2001.

[37] T. A. B. Snijders, A. Lomi, and V. J. Torló, “A model for the multiplex dynamics of two-mode and one-mode networks, with an application to employment preference, friendship, and advice," Social Networks, vol. 35, no. 2, pp. 265-276, 2013.

[38] S. Wasserman and K. Faust, Social Network Analysis: Methods and Applications, Cambridge University Press, Cambridge, UK, 1994.

[39] S. V. Buldyrev, R. Parshani, G. Paul, H. E. Stanley, and S. Havlin, "Catastrophic cascade of failures in interdependent networks," Nature, vol. 464, no. 7291, pp. 1025-1028, 2010.

[40] P. Wang, G. Robins, P. Pattison, and E. Lazega, "Exponential random graph models for multilevel networks," Social Networks, vol. 35, no. 1, pp. 96-115, 2013.

[41] J. McGlashan, K. de la Haye, P. Wang, and S. Allender, "Collaboration in complex systems: multilevel network analysis for community-based obesity prevention interventions," Scientific Reports, vol. 9, no. 1, Article ID 12599, 2019.

[42] G. Carnabuci and J. Bruggeman, "Knowledge specialization, knowledge brokerage and the uneven growth of technology domains," Social Forces, vol. 88, no. 2, pp. 607-641, 2009.

[43] Z. Lin, H. Yang, and B. Arya, "Alliance partners and firm performance: resource complementarity and status association," Strategic Management Journal, vol. 30, no. 9, pp. 921-940, 2009.

[44] A. Nerkar and S. Paruchuri, "Evolution of R\&D capabilities: the role of knowledge networks within a firm," Management Science, vol. 51, no. 5, pp. 771-785, 2005.

[45] I. Guler and M. F. Guillén, "Home country networks and foreign expansion: evidence from the venture capital industry," Academy of Management Journal, vol. 53, no. 2, pp. 390-410, 2010.

[46] M. Tortoriello, R. Reagans, and B. McEvily, "Bridging the knowledge gap: the influence of strong ties, network cohesion, and network range on the transfer of knowledge between organizational units," Organization Science, vol. 23, no. 4, pp. 1024-1039, 2012.

[47] R. S. Burt, Structural Holes: The Social Structure of Competition, Harvard University Press, Cambridge, UK, 2009.

[48] J. B. Barney, "Looking inside for competitive advantage," Academy of Management Perspectives, vol. 9, no. 4, pp. 49-61, 1995.

[49] T. S. Kuhn, The Structure of Scientific Revolutions, University of Chicago press, Chicago, IL, USA, 2012.

[50] I. Nonaka and H. Takeuchi, The Knowledge Creating Company, Harvard Business Review, New York, NY, USA, 1995.

[51] M. Reinholt, T. Pedersen, and N. J. Foss, "Why a central network position isn't enough: the role of motivation and ability for knowledge sharing in employee networks," 
Academy of Management Journal, vol. 54, no. 6, pp. 12771297, 2011.

[52] R. Reagans and B. McEvily, "Network structure and knowledge transfer: the effects of cohesion and range," Administrative Science Quarterly, vol. 48, no. 2, pp. 240-267, 2003.

[53] A. Stirling, "A general framework for analysing diversity in science, technology and society," Journal of the Royal Society Interface, vol. 4, no. 15, pp. 707-719, 2007.

[54] L. Fleming, "Recombinant uncertainty in technological search," Management Science, vol. 47, no. 1, pp. 117-132, 2001.

[55] S. E. Page, The Difference: How the Power of Diversity Creates Better Groups, Firms, Schools, and Societies, Princeton University Press, Princeton, NJ, USA, 2008.

[56] P. G. Audia and J. A. Goncalo, "Past success and creativity over time: a study of inventors in the hard disk drive industry," Management Science, vol. 53, no. 1, pp. 1-15, 2007.

[57] B.-W. Lin, C.-J. Chen, and H.-L. Wu, "Patent portfolio diversity, technology strategy, and firm value," IEEE Transactions on Engineering Management, vol. 53, no. 1, pp. 17-26, 2006.

[58] Y.-F. Huang and C.-J. Chen, "The impact of technological diversity and organizational slack on innovation," Technovation, vol. 30, no. 7-8, pp. 420-428, 2010.

[59] M. Tortoriello, B. McEvily, and D. Krackhardt, "Being a catalyst of innovation: the role of knowledge diversity and network closure," Organization Science, vol. 26, no. 2, pp. 423-438, 2015.

[60] J. Suzuki and F. Kodama, "Technological diversity of persistent innovators in Japan," Research Policy, vol. 33, no. 3, pp. 531-549, 2004.

[61] P. J. Lane and M. Lubatkin, "Relative absorptive capacity and interorganizational learning," Strategic Management Journal, vol. 19 , no. 5, pp. 461-477, 1998.

[62] G. Ahuja and R. Katila, "Technological acquisitions and the innovation performance of acquiring firms: a longitudinal study," Strategic Management Journal, vol. 22, no. 3, pp. 197-220, 2001.

[63] M. Hora and R. D. Klassen, "Learning from others' misfortune: factors influencing knowledge acquisition to reduce operational risk," Journal of Operations Management, vol. 31, no. 1-2, pp. 52-61, 2013.

[64] F. Polidoro, G. Ahuja, and W. Mitchell, "When the social structure overshadows competitive incentives: the effects of network embeddedness on joint venture dissolution," Academy of Management Journal, vol. 54, no. 1, pp. 203-223, 2011.

[65] J. Barney, "Firm resources and sustained competitive advantage," Journal of Management, vol. 17, no. 1, pp. 99-120, 1991.

[66] R. Crescenzi, M. Nathan, and A. Rodríguez-Pose, "Do inventors talk to strangers? On proximity and collaborative knowledge creation," Research Policy, vol. 45, no. 1, pp. 177-194, 2016.

[67] R. M. Grant and C. Baden-Fuller, "A knowledge-based theory OF inter-firm collaboration," Academy of Management Proceedings, vol. 1, pp. 17-21, 1995.

[68] X. Xie, H. Zou, and G. Qi, "Knowledge absorptive capacity and innovation performance in high-tech companies: a multimediating analysis," Journal of Business Research, vol. 88, pp. 289-297, 2018.

[69] R. A. Boschma and A. L. J. Ter Wal, "Knowledge networks and innovative performance in an industrial district: the case of a footwear district in the South of Italy," Industry \& Innovation, vol. 14, no. 2, pp. 177-199, 2007.
[70] B. Nooteboom, Learning and Innovation in Organizations and Economies, Oxford University Press, Oxford, UK, 2000.

[71] U. Cantner and A. Meder, "Technological proximity and the choice of cooperation partner," Journal of Economic Interaction and Coordination, vol. 2, no. 1, pp. 45-65, 2007.

[72] T. Broekel and R. Boschma, "Knowledge networks in the Dutch aviation industry: the proximity paradox," Journal of Economic Geography, vol. 12, no. 2, pp. 409-433, 2011.

[73] M. M. Keupp and O. Gassmann, "Resource constraints as triggers of radical innovation: longitudinal evidence from the manufacturing sector," Research Policy, vol. 42, no. 8, pp. 1457-1468, 2013.

[74] V. Gilsing, B. Nooteboom, W. Vanhaverbeke, G. Duysters, and A. van den Oord, "Network embeddedness and the exploration of novel technologies: technological distance, betweenness centrality and density," Research Policy, vol. 37, no. 10, pp. 1717-1731, 2008.

[75] D. R. Gnyawali and R. Madhavan, "Cooperative networks and competitive dynamics: a structural embeddedness perspective," Academy of Management Review, vol. 26, no. 3, pp. 431-445, 2001.

[76] R. S. Burt, "Structural holes and good ideas," American Journal of Sociology, vol. 110, no. 2, pp. 349-399, 2004.

[77] R. Gulati, "Does familiarity breed trust? The implications of repeated ties for contractual choice in alliances," Academy of Management Journal, vol. 38, no. 1, pp. 85-112, 1995.

[78] A. Zayed, A. Serag, and M. A. Farag, "Cynara cardunculus L.: outgoing and potential trends of phytochemical, industrial, nutritive and medicinal merits," Journal of Functional Foods, vol. 69, p. 103937, 2020.

[79] Z. Griliches, "Patent statistics as economic indicators: a survey," in R\&D and Productivity: The Econometric Evidence, pp. 287-343, University of Chicago Press, Chicago, IL, USA, 1998.

[80] A. Rangone, "A resource-based approach to strategy analysis in small-medium sized enterprises," Small Business Economics, vol. 12, no. 3, pp. 233-248, 1999.

[81] B. Lawson and D. Samson, "Developing innovation capability in organisations: a dynamic capabilities approach," International Journal of Innovation Management, vol. 5, no. 3, pp. 377-400, 2001.

[82] M. Vicente, J. L. Abrantes, and M. S. Teixeira, "Measuring innovation capability in exporting firms: the INNOVSCALE," International Marketing Review, vol. 32, no. 1, pp. 29-51, 2015.

[83] T. Tura, V. Harmaakorpi, and S. Pekkola, "Breaking inside the black box: towards a dynamic evaluation framework for regional innovative capability," Science and Public Policy, vol. 35, no. 10, pp. 733-744, 2008.

[84] L. C. Freeman, "Centrality in social networks conceptual clarification," Social Networks, vol. 1, no. 3, pp. 215-239, 1978.

[85] S. Borgatti, M. Everett, and L. Freeman, UCINET 6 for Windows: Social Network Analysis Software, Analytic Technologies, Harvard, MA, USA, 2002.

[86] R. Aalbers, W. Dolfsma, and O. Koppius, "Individual connectedness in innovation networks: on the role of individual motivation," Research Policy, vol. 42, no. 3, pp. 624-634, 2013.

[87] N. Salman and A.-L. Saives, "Indirect networks: an intangible resource for biotechnology innovation," $R$ and D Management, vol. 35, no. 2, pp. 203-215, 2005.

[88] C.-Y. Tseng, S.-C. Lin, D.-C. Pai, and C.-W. Tung, "The relationship between innovation network and innovation capability: a social network perspective," Technology Analysis \& Strategic Management, vol. 28, no. 9, pp. 1029-1040, 2016. 
[89] L.-c. Yin, H. Kretschmer, R. A. Hanneman, and Z.-y. Liu, "Connection and stratification in research collaboration: an analysis of the COLLNET network," Information Processing \& Management, vol. 42, no. 6, pp. 1599-1613, 2006.

[90] R. Blundell, R. Griffith, and J. V. Reenen, "Dynamic count data models of technological innovation," The Economic Journal, vol. 105, no. 429, pp. 333-344, 1995.

[91] J. Guan, J. Zhang, and Y. Yan, "The impact of multilevel networks on innovation," Research Policy, vol. 44, no. 3, pp. 545-559, 2015.

[92] M. Delgado-Verde, G. Martín-de Castro, and J. Emilio NavasLópez, "Organizational knowledge assets and innovation capability," Journal of Intellectual Capital, vol. 12, no. 1, pp. 5-19, 2011.

[93] O. Sorenson, J. W. Rivkin, and L. Fleming, "Complexity, networks and knowledge flow," Research Policy, vol. 35, no. 7, pp. 994-1017, 2006.

[94] J. Sydow, G. Schreyögg, and J. Koch, "Organizational path dependence: opening the black box," Academy of Management Review, vol. 34, no. 4, pp. 689-709, 2009. 